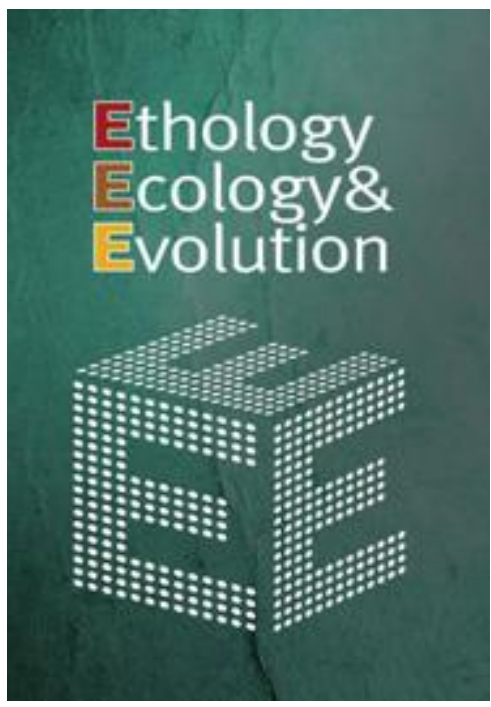

\title{
Cryptochrome 1a Localisation in Light- and Dark-Adapted Retinae of Several Migratory and Non-Migratory Bird Species: No Signs of Light-Dependent Activation
}

\begin{tabular}{|c|c|}
\hline Journal: & Ethology Ecology \& Evolution \\
\hline Manuscript ID & TEEE-2020-0134.R1 \\
\hline Manuscript Type: & Original Article \\
\hline $\begin{array}{r}\text { Date Submitted by the } \\
\text { Author: }\end{array}$ & 22-Dec-2020 \\
\hline Complete List of Authors: & $\begin{array}{l}\text { Bolte, Petra; Carl von Ossietzky University of Oldenburg, Institute for } \\
\text { Biology and Environmental Sciences } \\
\text { Einwich, Angelika; Carl von Ossietzky University of Oldenburg, Institute } \\
\text { for Biology and Environmental Sciences } \\
\text { Seth, Pranav; Carl von Ossietzky University of Oldenburg, Institute for } \\
\text { Biology and Environmental Sciences } \\
\text { Chetverikova, Raisa; Carl von Ossietzky University of Oldenburg, } \\
\text { Institute for Biology and Environmental Sciences } \\
\text { Heyers, Dominik; Carl von Ossietzky University of Oldenburg, Institute } \\
\text { for Biology and Environmental Sciences } \\
\text { Wojahn, Irina; Carl von Ossietzky University of Oldenburg, Institute for } \\
\text { Biology and Environmental Sciences } \\
\text { Janssen-Bienhold, Ulrike; Carl von Ossietzky University of Oldenburg, } \\
\text { Department of Neuroscience } \\
\text { Feederle, Regina; Helmholtz Zentrum München Deutsches } \\
\text { Forschungszentrum für Gesundheit und Umwelt, Institute for Diabetes } \\
\text { and Obesity } \\
\text { Hore, Peter; University of Oxford, Department of Chemistry } \\
\text { Dedek, Karin; Carl von Ossietzky University of Oldenburg, Institute for } \\
\text { Biology and Environmental Sciences } \\
\text { Mouritsen, Henrik; Carl von Ossietzky University of Oldenburg, Institute } \\
\text { for Biology and Environmental Sciences }\end{array}$ \\
\hline Keywords: & magnetic orientation, magnetoreception, magnetic sense, cryptochrome, \\
\hline
\end{tabular}


1

2

3

4

5

6

7

8

9

10

11

12

13

14

15

16

17

18

19

20

21

22

23

24

25

26

27

28

29

30

31

32

33

34

35

36

37

38

39

40

41

42

43

44

45

46

47

48

49

50

51

52

53

54

55

56

57

58

59

60 bird navigation, light adaptation, Erithacus rubecula

\section{SCHOLARONE \\ Manuscripts}




\title{
Cryptochrome 1a localisation in light- and dark-adapted retinae of several migratory and non-migratory bird species: No signs of light-dependent activation
}

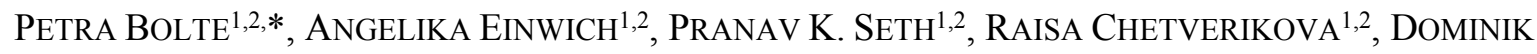 \\ HEYERS $^{1,2}$, IRINA WOJAHN ${ }^{1,2}$, UlRIKE JANSSEN-BIENHOLD ${ }^{2,3}$, REGINA FEEDERLE ${ }^{4}$, P. J. HORE ${ }^{5}$, KARIN \\ DEDEK $^{1,2}$ and HENRIK MOURITSEN ${ }^{1,2}$
}

${ }^{1}$ Institute for Biology and Environmental Sciences, Carl-von-Ossietzky-University Oldenburg, Carlvon-Ossietzky-Straße 9-11, 26129 Oldenburg, Germany

${ }^{2}$ Research Centre for Neurosensory Sciences, Carl-von-Ossietzky-University Oldenburg, Carl-vonOssietzky-Straße 9-11, 26129 Oldenburg, Germany

${ }^{3}$ Department of Neuroscience, Carl-von-Ossietzky-University Oldenburg, Carl-von-Ossietzky-Straße 9-11, 26129 Oldenburg, Germany

${ }^{4}$ Institute for Diabetes and Obesity, Monoclonal Antibody Core Facility, Helmholtz Zentrum München, German Research Center for Environmental Health, Ingolstädter Landstr. 1, 85764 Neuherberg, Germany

${ }^{5}$ Department of Chemistry, University of Oxford, South Parks Road, Oxford OX1 3QZ, United Kingdom

\footnotetext{
*Corresponding author: Petra Bolte, Research Centre for Neurosensory Sciences, Carl-von-OssietzkyUniversity Oldenburg, Carl-von-Ossietzky-Straße 9-11, 26129 Oldenburg, Germany (E-mail: petra.bolte@uni-oldenburg.de).
} 
KEY WORDS: magnetic orientation, magnetoreception, magnetic sense, cryptochrome, bird navigation, light adaptation, Erithacus rubecula.

RUNNING HEAD: No signs of light-dependent Cryla activation in birds

\section{INTRODUCTION}

Fifty years ago, it was shown that European robins use a magnetic compass for navigation (Wiltschko 1968). Subsequently, magnetic orientation has been confirmed in many other bird species (Wiltschko \& Wiltschko 1972, 1995a; Cochran et al. 2004; Mouritsen 2013, 2018). Magnetic orientation in nightmigratory songbirds is light-dependent (Wiltschko et al. 1993, 2010) and sensitive to radio-frequency 
magnetic fields (Ritz et al. 2004; Engels et al. 2014; Schwarze et al. 2016; Kobylkov et al. 2020). Cluster N, a part of the avian visual wulst, processes magnetic compass information (Zapka et al. 2009, 2010; Mouritsen et al. 2016) originating from both eyes (Hein et al. 2010, 2011; Engels et al. 2012). This strongly indicates that magnetic compass detection in night-migratory songbirds is lightdependent and processed in the birds' visual system. However, the molecular mechanisms enabling migratory birds to perceive the geomagnetic field are still unknown. Of the various hypotheses that have been suggested, the most promising is a physical, quantum-mechanical mechanism. This socalled radical pair theory suggests that photon absorption in specialised magnetoreceptor molecules leads to electron transfer reactions and the subsequent formation of a long-lived radical pair (Schulten et al. 1978; Ritz et al. 2000; Maeda et al. 2008; Hore \& Mouritsen 2016). The theory suggests that the radical-pair exists in electron spin-correlated singlet or triplet states, which interconvert due to nuclear spin interactions and effects of the external magnetic field. Thus, the geomagnetic field can influence the proportions of singlet and triplet reaction yields, which in turn can function as a chemical compass (Schulten et al. 1978; Ritz et al. 2000, 2009; Solov’yov et al. 2010, 2014; Mouritsen \& Hore 2012; Engels et al. 2014; Hore \& Mouritsen 2016). So far, the only known proteins that could serve as magnetoreceptors in vertebrates are the cryptochromes. They have been found in birds' retinae where they can be photoexcited to form radical pairs (Ritz et al. 2000; Liedvogel et al. 2007; Biskup et al. 2009; Liedvogel \& Mouritsen 2009; Rodgers \& Hore 2009; Maeda et al. 2012; Lee et al. 2014; Hiscock et al. 2016). Cryptochromes are flavo-proteins that are closely related to photolyases. Both protein classes contain the cofactor flavin adenine dinucleotide (FAD) (Cashmore et al. 1999). While photolyases are involved in DNA repair via electron transfer mechanisms (Hsu et al. 1996; Ozturk et al. 2007), some cryptochromes serve as core components of the circadian clock in vertebrates (Cashmore et al. 1999; Sancar 2000, 2004). In the avian retina, six members of the cryptochrome family have been described so far: Cryla is found in the UV/V-sensitive cones (Nießner et al. 2011), Crylb is localised in the photoreceptor inner segments, ganglion cells, and displaced ganglion cells (Bolte et al. 2016; Nießner et al. 2016), Cry2 proteins (Cry2a: Bailey et al 2002; Möller et al. 2004; and Cry2b: Hochstoeger et al. 2020) are ubiquitously expressed in all avian retinal cell types (Einwich et al. unpublished data) and Cry4 proteins have been detected in the photoreceptor double cones and 
long-wavelength single cones of migratory European robins and chicken (Günther et al. 2018; Wu et al. 2020). A recent paper reported an entirely different Cry4 staining pattern in the retina of pigeons (Hochstoeger et al. 2020). Cry4 is expressed in at least two different isoforms, Cry4a and Cry4b (Einwich et al. 2020). Currently, Cry4 is considered to be the most likely light-dependent magnetoreceptor underlying the avian magnetic compass since it possesses the most favourable retinal localisation and expression pattern (Günther et al. 2018) and might be the only cryptochrome that is able to bind FAD (Ozturk et al. 2009; Kutta et al. 2017; Wang et al. 2018), which is a prerequisite for a functional radical-pair mechanism. However, it cannot be excluded that that Cryla could bind FAD in vivo, and as long as a definite proof has not been delivered on which protein is the primary avian magnetoreceptor, Cry 1a remains a possible candidate. Cryla has been suggested to be excited by blue light to form radical pairs that might last long enough for magnetic fields to affect singlet-triplet interconversion (Liedvogel et al. 2007). Furthermore, the claimed presence of Cryla immunoreactivity in light- but not in dark-adapted bird retinae as well as different Cryla antibody staining intensities between retinae after exposure to different wavelengths suggest that a C-terminal Cryla antibody only recognises a light-activated form of Cryla (Nießner et al. 2013, 2014, 2018). A definitive demonstration of a light-activated conformational change in Cryla that could be detected by antibody stainings would neither prove that Cryla is the magnetoreceptor (it could just mean that Cryla has some other light-activated function) nor prove that FAD is bound to it (it could serve a non-FAD mediated function). Yet, it would be a valuable piece of evidence which could be an important part of the puzzle to understand the functional role of Cry la in the avian retina.

Moreover, immunohistochemical data without the availability of knock-out animals should be interpreted with caution since it is possible that the antibody detects proteins other than the targeted protein. In non-standard animals like wild-caught migratory birds, it is necessary to verify immunohistochemical data using different antibodies to compensate for the lack of knock-out controls. The aim of the present study was therefore to test whether we could independently confirm the restricted localisation of Cryla in UV/V cone outer segments in five different bird species with three different carefully designed and well-controlled antibodies, including the one used by Nießner et al. (2011). Furthermore, we tested whether we could confirm the reported differences in Cryla staining 
intensity between light- and dark-adapted retinae of the chicken as described by Nießner and colleagues (Nießner et al. 2013), and thus that C-terminal Cryla antibodies can be used to recognise a light-activated form of Cryla.

\section{METHODS}

Birds

Tissues from a total of 38 birds were used in this study: 24 European robins (Erithacus rubecula), two Eurasian blackcaps (Sylvia atricapilla), one zebra finch (Taeniopygia guttata), six pigeons (Columba livia domestica) and three domestic chickens (Gallus gallus domesticus). For the whole-mounted stainings we used two hybrids of wild red junglefowl (Gallus gallus gallus) and domestic chicken breed Welsumer Bantam (Gallus gallus domesticus). European robins and Eurasian blackcaps were wild-caught in the vicinity of the Oldenburg University campus using mist nets. The pigeons and the zebra finch were captive-bred. The chickens were bred from specific-pathogen-free eggs (VALO Biomedia, Osterholz-Scharmbeck, Germany) and raised in our animal facility. The birds were kept indoors under the natural light-dark cycle.

\section{Tissue dissection}

For vertical retina sections, the birds were either dark-adapted for $2 \mathrm{hr}$ and sacrificed after sunset (polyclonal Cryla antibodies) or sacrificed at different time points during the day under normal ambient light conditions present in the laboratory (Cryla-3E12 antibody). For immunohistochemistry, the birds were either anaesthetized and transcardially perfused with saline followed by $4 \%$ paraformaldehyde in phosphate buffered saline (PFA/PBS; for the polyclonal Cryla antibodies) or, with the exception of pigeons, sacrificed by decapitation (for the Cryla-3E12 antibody). The pigeons were sacrificed by an overdose of either Narcoren. The eyes were enucleated, and the cornea, lens and vitreous were removed from the eyecup.

For the whole-mounted retina samples, two chickens and three European robins were used. All four birds were sacrificed during the daytime in the period from 14:00 to 15:00 CET. Prior to the experiment, all birds were kept indoors under normal daylight conditions. One chicken and one robin 


\section{Tissue preparation}

After preparation, the eyecups were post-fixed in 4\% PFA/PBS for $20 \mathrm{~min}$ and washed in PBS. Tissue adaptation to cryoprotectant solution was performed overnight at $4{ }^{\circ} \mathrm{C}$ in $30 \%$ saccharose solution in $0.1 \mathrm{M}$ phosphate buffer (PB). The eyecups were embedded in cryoblock at $-20^{\circ} \mathrm{C}$. Vertical retinal sections of $20 \mu \mathrm{m}$ were cut on a cryostat (Leica), collected on gelatinized superfrost coverslips (Carl Roth, Karlsruhe, Germany), or Menzel SuperFrost Plus slides (Thermo Fisher Scientific) and heatfixed at $37^{\circ} \mathrm{C}$ for $2-3 \mathrm{hr}$.

For the whole-mounted retina samples, the dissected eyecups were transferred to a dish containing Ringer's solution, where they were cut into smaller parts. The retina was separated from the pigment epithelium and mounted on filter paper $(0.8 \mu \mathrm{m}$ pore size; AABP; Merck Millipore, Schwalbach, Germany) with the photoreceptor side facing up. The retinae were fixed in 2\% PFA/PBS for 30 min and washed in $0.1 \mathrm{M}$ PB.

\section{Antibodies}

Antibodies against Cryla. We produced two different antibodies against Cryla, one polyclonal (gwCry1a antibody) and one monoclonal (Cryla-3E12 antibody, see Table 1). Additionally, we tested the polyclonal Cryla antibody used in the study of Nießner et al. (2011, kindly provided by Prof. R. Wiltschko, Fachbereich Biowissenschaften of J.W. Goethe-Universität, Frankfurt am Main, Germany). Our polyclonal gwCryla antibody was designed against a 25 amino acid (aa) peptide at the C-terminal end of the garden warbler/European robin Cryla protein sequence (position 565-589, GenBank accession number CAG14931) and was custom-made by Pineda Antibody Service (Berlin, Germany). For the generation of the monoclonal antibody (Cry1a-3E12), a peptide comprising 21 aa from the Cryla C-terminal end was synthesised and coupled to ovalbumin (Ova) and biotin for 
immunisation and testing, respectively (Peps4LS, Heidelberg, Germany). Monoclonal antibody production was performed as described before (Günther et al. 2018). Supernatants from 36 clones, which were positive in ELISA on biotinylated peptide, were tested on retinal cryosections of European robin and chicken. Twenty-one clones showed no specific immunosignal. Of the remaining 15 clones, six stained all nuclear cell layers, four clones additionally the inner photoreceptor segments (IS), two clones only the IS, one clone IS and outer plexiform layer, one clone stained only the outer plexiform layer. One clone stained the photoreceptor outer segments. Due to the results of Nießner et al. (2011), we chose the clone 3E12 (outer segment staining) for further work. Additionally, we selected the clone 6E6 (inner segment staining), since seven out of 15 clones stained the photoreceptor inner segments. The hybridoma cells of these two Cry la-reactive supernatants were cloned twice by limiting dilution. The IgG subclass was determined in an ELISA assay with mouse anti-rat kappa light chain antibodies (TIB172, ATCC) as capture and HRP-coupled mouse anti-rat IgG subclass-specific antibodies for detection. As the clone 6E6 did not pass the specificity controls, only cell culture supernatant of Cry1a-3E12 (rat IgG1/k) was used in this study.

Antibodies against avian UV/V cone opsin. For staining the avian UV/V cone opsin, we used three different commercially available antibodies, which were raised against (three different) peptides encoded by OPN1SW of human origin, OPN1SW-N20, OPN1SW-P13 and anti-SW Opsin (EMD Millipore; Cat\#: AB5407). For the antibody anti-SW Opsin (Millipore) the peptide sequence was not publicly available (see Table 1). We performed several controls to confirm the specificity of the antiSW Opsin AB5407, OPN1SW-N20 and the OPN1SW-P13 antibody to avian UV/V cone opsin. The OPN1SW-N20 antibody showed no co-localisation with rhodopsin Rho1D4 (Cell Essentials, Boston, MA, USA) in European robin retinal sections but did recognise recombinantly expressed ggUVopsinGFP fusion proteins from transfected HEK cells. By double-staining of the OPN1SW-P13 antibody with rhodopsin Rho1D4 as well as with the monoclonal antibody against chicken blue opsin (Günther et al. 2018) on European robin and chicken retinal sections, we confirmed that the OPN1SW-P13 antibody neither stains rods nor blue cones. For the whole-mounted retina samples, two combinations of antibodies were used: Cry1a-3E12 and anti-SW Opsin AB5407 (Fig. 5A-F); and Cry1a-3E12 and 


\section{Immunofluorescent staining}

For the staining with the polyclonal anti-Cry la antibodies, the retinal pigment epithelium was bleached by immersing the retinal sections for $30 \mathrm{~min}$ in $5 \mathrm{~mL} 1.8 \% \mathrm{NaCl}, 4 \mathrm{~mL} 30 \% \mathrm{H}_{2} \mathrm{O}_{2}, 1 \mathrm{~mL}$ $\mathrm{H}_{2} \mathrm{O}$ and one drop of $\mathrm{NH}_{3}$ (aq.). After washing in PBS, cryosections were blocked with $10 \%$ normal donkey serum (NDS, Sigma-Aldrich) in PBS containing 0.3\% Tween and 2\% BSA for $1 \mathrm{hr}$ and then incubated with primary antibodies at $4{ }^{\circ} \mathrm{C}$ overnight. The antibodies were diluted in PBS containing $0.3 \%$ Tween, $2 \%$ BSA and $2 \%$ NDS. For the Cry $1 \mathrm{a}-3 \mathrm{E} 12 \mathrm{mAb}$, either PBS with $0.3 \%$ Triton X-100 or PB with $0.3 \%$ Triton X-100 and 1\% BSA was used as incubation buffer. After washing, the slides were blocked in buffer with $10 \%$ NDS for 30 to 60 min. Incubation with the primary antibody (in the presence of $2 \%$ NDS) was performed overnight at $4{ }^{\circ} \mathrm{C}$. For the polyclonal gwCryla antibody, the slides were incubated with a biotinylated mouse anti-rabbit secondary antibody (1:200; Invitrogen) and with Streptavidin Alexa Fluor 488-conjugate (Invitrogen, Karlsruhe, Germany) for signal detection ( $2 \mathrm{hr}$ each). For the monoclonal antibodies, the sections were first incubated with a IgG1 mouse anti rat antibody (1:10) for $1 \mathrm{hr}$, and, after washing, with appropriate secondary antibodies conjugated to the fluorescent dyes Alexa 488, Alexa 555, Alexa 568 or Alexa 647 (Invitrogen), respectively, for 1 to $2 \mathrm{hr}$. For both polyclonal and monoclonal Cryla antibodies, fluorescent doublestaining with an antibody against UV/V cone opsin (OPN1SW, see Table 1) was performed. In control experiments, the Cryla primary antibodies were pre-adsorbed with the appropriate inhibitory peptide 
(ratio 1:10) for $4 \mathrm{hr}$, centrifuged, and the supernatant was applied to the sections. All sections were covered with Vectashield Mounting Medium (Vector Laboratories Inc., Burlingame, CA, USA) and a cover slip.

The whole-mounted retinae were blocked with $10 \%$ NDS in $0.1 \mathrm{M}$ PB containing $0.5 \%$ Triton X-100 and $0.05 \% \mathrm{NaN}_{3}$ at $4{ }^{\circ} \mathrm{C}$ overnight. The incubation with the primary antibodies (1:2 dilution for Cry1a-3E12, 1:500 dilution for anti-SW Opsin AB5407 and OPN1SW-P13) was performed at $4{ }^{\circ} \mathrm{C}$ for 5 days. After washing with $0.1 \mathrm{M}$ PBS, the retinae were incubated overnight with a biotinylated donkey anti-rat antibody (1:500; Abcam, Cambridge, UK). After washing, DyLight 649 streptavidin (Vector Laboratories) and Alexa 568 donkey anti-rabbit antibodies were applied overnight (1:500). Following several washing steps, retinae were mounted on microscope slides and covered with AquaPoly/Mount medium (Polysciences, Inc., Warrington, PA, USA) and a cover slip.

\section{DAB stainings}

Sections were stained against Cryla using the immuno-ABC-technique described previously (Heyers et al. 2007). Endogenous peroxidases were inactivated with $0.3 \% \mathrm{H}_{2} \mathrm{O}_{2}$ for $1 \mathrm{hr}$. Unspecific binding sites were saturated by incubation with $10 \%$ normal goat serum (NGS; Vector Laboratories, Burlingame, CA, USA) dissolved in PBS containing 0.3\% Triton-X100 (PBS-T; Sigma-Aldrich) for 1 hr. After washing, sections were incubated with the polyclonal gwCryla antibody (1:200 in PBS-T) or pre-immune serum (1:5,000 in PBS-T) for $48 \mathrm{hr}$. Sections were sequentially incubated with a biotinylated secondary antibody and an avidin-conjugated peroxidase complex (Vector Laboratories). Peroxidase activity was detected using a 3,3'-diaminobenzidine (DAB; Sigma-Aldrich) reaction with hydrogen peroxidase substituted by $\beta$-D-glucose oxidase (Sigma-Aldrich) (Shu et al. 1988; Heyers et al. 2008). Stained sections were dehydrated in a graded series of alcohol solutions (ethanol 70, 96, 100\%) and embedded in Eukitt (Sigma-Aldrich).

Cloning of the European robin UVopsin cDNA sequence 
The total RNA of one retina each was isolated using the TRIzol Reagent (Life Technologies, Carlsbad, CA, USA) according to the manufacturer's instructions. After DNase I treatment (Invitrogen, Carlsbad, CA, USA), total RNA was copied into first-strand cDNA using Superscript III Reverse Transcriptase (Life Technologies) following the manufacturer's protocol. To amplify the coding region of erUVopsin, specific primers with restriction sites had been designed to anneal to evolutionary conserved regions identified after alignment of reported avian homologues. Sense $\left(5^{\prime}-\right.$ gtttctctcgaggccatggavgaggavgag-3') and antisense (5'-agaaacaagcttacagctggggecgacct-3') primers were used to amplify the entire coding region with the RT-PCR kit GoTaq Long PCR Master Mix (Promega, Madison, WI, USA). The cycle conditions were: one cycle denaturation at $95{ }^{\circ} \mathrm{C}(5 \mathrm{~min})$, 30 cycles at $94{ }^{\circ} \mathrm{C}(15 \mathrm{sec}), 57{ }^{\circ} \mathrm{C}$ (gene-specific temperature, $\left.30 \mathrm{sec}\right), 72{ }^{\circ} \mathrm{C}(90 \mathrm{sec})$, with a final extension of $10 \mathrm{~min}$ at $72{ }^{\circ} \mathrm{C}$. After purification using the QIAquick PCR Purification Kit (Qiagen, Hilden, Germany), PCR products of the appropriate length were cloned into pGEM ${ }^{\circledR}$-T Easy vector (Promega) for subsequent sequencing by an external contractor (LGC Genomics, Berlin, Germany). The amplified sequences were cut with XhoI/HindIII restriction enzymes (ThermoFisher Scientific, Waltham, MA, USA) and cloned into the expression vector pTurboGFP-N (Evrogen, Moscow, Russia) according to the protocol for the Rapid DNA Dephos \& Ligation Kit (Roche Diagnostics, Rotkreuz, Switzerland). DNA identity and similarities between the individuals were analysed with Clustal Omega (EMBL-EBI).

\section{Cell culture and protein expression}

HEK cells were maintained in DMEM with 10\% FCS and 1\% antibiotics/antimycotics (SigmaAldrich). For immunocytochemistry, the cells were plated in 24-well plates on glass coverslips that had been treated with poly L-Lysine for $30 \mathrm{~min}$. For immunoblot analysis, the cells were seeded in 6well plates (Roth). erCryla, erCrylb (Bolte et al. 2016), gwCryla, gwCrylb (Liedvogel et al. 2007), erUVopsin (this paper) and ggUVopsin (Günther et al. 2018) were expressed as fusion proteins with GFP from the respective generated pTurbo-GFP-N vectors using $2 \mu$ l Lipofectamine 2000 reagent (Invitrogen) per $\mu \mathrm{g}$ DNA in OptiMEM medium (Life Technologies, Carlsbad, CA, USA) following the manufacturer's protocol. For immunoblot analysis using the gwCryla antibody, gwCryla and 
gwCrylb proteins without a GFP tag were recombinantly expressed in a Sf9/baculovirus expression system as described previously (Liedvogel et al. 2007).

\section{Immunocytochemistry of transfected cells}

Twenty-four or $48 \mathrm{hr}$ after transfection, the cells were washed in PBS followed by fixation with icecold methanol (7 min) or 4\% PFA (15 min). After washing, the cells were incubated for 20 to $30 \mathrm{~min}$ with PBS including $0.1 \%$ Triton X-100, and washed again. Optionally, the cells were blocked with $10 \%$ NDS in PBS for $1 \mathrm{hr}$. Incubation with the primary antibodies was performed at $4{ }^{\circ} \mathrm{C}$ overnight (for dilutions, see Table 1). The monoclonal erCry la antibodies were additionally enhanced with mouse anti-rat IgG1 for $2 \mathrm{hr}$ at room temperature. After washing, the cells were incubated for $2 \mathrm{hr}$ with Alexa 555- or 568-conjugated anti-mouse secondary antibodies (1:500 in PBS) and mounted with Vectashield.

\section{Protein sample generation and immunoblot analysis}

Polyclonal anti-gwCryla antibody. The specificity of the rabbit polyclonal anti-gwCry 1a antibody for the retina of European robin was accessed by SDS-PAGE and immunoblot analysis, as reported before (Kranz et al. 2013). Briefly, $50 \mu \mathrm{g}$ of total protein lysates of gwCryla- and gwCrylb-transfected HEK cells as well as fractionated total protein lysates of European robin retinae were separated on $8-10 \%$ gradient gels $(150 \mathrm{~V}, 70 \mathrm{~min})$ and transferred (overnight $40 \mathrm{~V}$ at $\left.4{ }^{\circ} \mathrm{C}\right)$ to a nitrocellulose membrane (Optitran BA-S 85; Schleicher \& Schuell, Dassel, Germany). After blocking of non-specific binding sites for $1 \mathrm{hr}$ with $5 \%$ powdered milk in TBS-Tween $(10 \mathrm{mM}$ Tris/HCl, $150 \mathrm{mM} \mathrm{NaCl}, 0.1 \%$ Tween 20, pH 7.4) at $37^{\circ} \mathrm{C}$, the primary antibody was incubated (1:500 in TBS-Tween) overnight at $4{ }^{\circ} \mathrm{C}$. After washing, the blot was incubated with goat anti-rabbit IgG conjugated to HRP $(1: 3,000$ in TBSTween with 2\% powdered milk; BioRad Laboratories, Munich, Germany) for $2 \mathrm{hr}$. Immunoreactive proteins were visualised using a chemiluminescence detection system (Pierce ECL; Thermo Fisher Scientific, Rockford, IL) following the manufacturer's instructions. 
Monoclonal anti-Cryla antibody. Forty-eight hr after transfection, the cells were washed with cold PBS, harvested in $150 \mu 1$ sample buffer (10\% glycerol, $2 \%$ SDS, $1 \%$ beta-mercaptoethanol, $50 \mathrm{mM}$ Tris- $\mathrm{HCl} \mathrm{pH} 6.8 ; 12.5 \mathrm{mM}$ EDTA $\mathrm{pH}$ 8.0, $0.02 \%$ bromophenol blue), heated to $100{ }^{\circ} \mathrm{C}$ for $10 \mathrm{~min}$ and stored at $-20{ }^{\circ} \mathrm{C}$. For the retina homogenates, retinae were homogenised in HP2 buffer $(50 \mathrm{mM}$ Tris/HCl, pH 7.4, 2 mM EGTA, pH 7.4, 2 mM EDTA, pH 7.4, 0.1 mM sodium orthovanadate, $1 \mathrm{mM}$ DTT, $2 \mu \mathrm{g} / \mathrm{mL}$ leupeptin, $5 \mu \mathrm{g} / \mathrm{mL}$ aprotinin, $2 \mathrm{mM}$ PMSF in DMSO, Roche cOmplete ${ }^{\mathrm{TM}}$ Protease Inhibitor Cocktail) on ice, rotated for $1 \mathrm{hr}$ at $4{ }^{\circ} \mathrm{C}$ and centrifuged for 20 min at $4{ }^{\circ} \mathrm{C}$ and $12,000 \mathrm{rpm}$ in a Eppendorf 5417R centrifuge. The supernatant was used for further work. Total protein concentration was measured by the Neuhoff assay (Neuhoff et al. 1979). Proteins were analysed by standard SDS-PAGE (10\% acrylamide, with a 4\% acrylamide stacking gel). Fifteen $\mu \mathrm{g}$ of HEK cell homogenates (in sample buffer), $23 \mu \mathrm{g}$ of European robin and $60 \mu \mathrm{g}$ of domestic chicken retina homogenate (mixed with Roti ${ }^{\circledR}-L o a d 2$, Carl Roth, where DTT had been added as a reducing agent) were loaded onto the gel. Gel electrophoresis was performed in an Eco Mini Buffer Tank (Biorad) using a $160 \mathrm{~V}$ separation current. Protein transfer from gel to membrane was performed in a wet blot system (350 mA for $60 \mathrm{~min}$ ). After blocking of the nitrocellulose membrane (Whatman, SigmaAldrich) for $1 \mathrm{hr}$ in 5\% milk powder (Roth) in TBS-Tween, the membranes were incubated with primary antibodies diluted in TBS-Tween overnight at $4{ }^{\circ} \mathrm{C}$ (see Table $1 ; 1: 20$ dilution). The antibody was additionally enhanced with the anti-subclass-specific antibody mouse anti-rat IgG1 for $1 \mathrm{hr}$. After incubation with HRP-conjugated secondary antibodies (dilution of 1:1,000), a chemiluminescence procedure was performed with Super Signal West Pico chemiluminescent substrates (Thermo Fisher Scientific) and the Image Lab Software version 5.2.1 (BioRad).

\section{Image acquisition and measurements}

Confocal micrographs were taken with Leica TCS confocal microscopes (SP2, SP5 and SP8) using a 63×/1.32 plan apochromat objective, an HCX PL APO 100.0×1.40 OIL objective, or HC PL APO CS2 63/1.4 and 40/1.3 objectives. The whole-mounted retinae micrographs were taken with Leica TCS SP8 using an HC PL APO CS2 40×/1.30 OIL objective. The laser and scanning settings (laser intensity, 
detector gain, etc.) as well as pixel size and resolution were kept constant among all micrographs of the whole-mounted retinae.

Images are presented either as single scans or maximum projections of confocal stacks. For high resolution scans of photoreceptor outer segments, Nyquist sampling was performed and confocal stacks were subjected to deconvolution with theoretical point spread functions using Huygens Essential deconvolution software (SVI, Hilversum, Netherlands) and processed in brightness and contrast using Fiji (https://fiji.sc/; RRID:SCR_002285). Image acquisition and processing of antibody staining and controls from the same experiment were done with identical settings. The pixel size was adjusted for each experiment and kept constant between different conditions. The diameter of 23 Cryla labelled dots was measured in maximum projections of deconvolved stacks of Fig. 2C (antibody Cry1a-Frankfurt from Nießner et al. 2011) and Fig. 3E (antibody Cry1a-3E12) using Fiji.

\section{RESULTS}

In their 2011 study, Nießner and colleagues found Cryla immunoreactivity in the retinae of the European robin (Erithacus rubecula) and the domestic chicken (Gallus gallus domesticus) exclusively in the outer segments of the UV/V cones [Nießner et al. 2011; polyclonal antibody directed against a peptide at amino acid (aa) position 600-618]. When this study was published, we already had generated a polyclonal anti-Cryla antibody (named gwCryla antibody) that is specific to a 25 aa long peptide at the near-C-terminal end of the Cryla protein (aa 565-589, see Table 1). The peptide sequence recognised by the gwCryla antibody is identical in the garden warbler (Sylvia borin) and the European robin (Liedvogel et al. 2007; Bolte et al. 2016). This antibody showed contradictory results in immunohistochemical stainings: fluorescent stainings gave a strong immunosignal at the outer limiting membrane (Fig. 1A, C-D, green) of the European robin retina (Fig. 1B). In contrast, stainings with the chromogenic reporter 3,3'-diaminobenzidine (DAB) revealed Cryla signals in specific photoreceptor outer segments of the European robin retina (Fig. 1G).

Using the gwCryla antibody with the DAB method, we stained specific photoreceptor outer segments in the domestic pigeon (Columba livia domestica, see Fig. S1A-D in Supplemental Data) and in the 
(non-migratory) zebra finch (Taeniopygia guttata, Fig. S1E-H in Supplemental Data). In both species, the gwCryla antibody also showed signals close to the outer limiting membrane.

We validated the specificity of the gwCryla antibody by performing the following controls. Staining of the European robin retina with the pre-immune serum instead of the primary antibody revealed that there was no immunosignal caused by antibodies that had already been present in the animal before immunisation (Fig. 1E, H). Blocking by pre-incubation with peptides used for immunisation indicated that the antibody did not bind to peptides other than the immunisation peptide (Fig. 1F). There is extensive diffuse background staining visible close to the outer segments. However, this staining is not located in the UV/V cone outer segments since it does not co-localise with the staining of the UV/V cone opsin marker antibody OPN1SW-P13 (magenta). In immunoblots, a protein of the expected size $(69.7 \mathrm{kDa})$ was found in all fractions of the European robin retina (Fig. 1I, left blot). Immunoblots on lysates of cells recombinantly expressing erCryla-GFP fusion proteins incubated with the gwCryla antibody showed two bands (Fig. 1I, middle blot). The lower band was absent in protein samples of erCry1b-GFP expressing HEK cells and GFP expressing HEK cells (Fig. 1I, middle blot). The additional upper band occurs in protein samples of erCryla-GFP, erCrylb-GFP and in GFP expressing HEK cells and therefore represents binding of the gwCryla antibody to another HEK cell protein. The lower erCryla-GFP specific band is slightly higher than the expected size of $96.2 \mathrm{kDa}$ for erCrylaGFP. Such variations of the molecular weight of proteins are often seen in immunoblots and might arise from erCryla protein oligomerisation, or posttranslational modification which would alter the molecular weight of the erCryla protein. The erCry 1a-GFP specific band was not detected in negative controls in which the gwCryla antibody was replaced by pre-immune serum (Fig. 1I, right blot). Immunocytochemistry on HEK cells (Fig. 1J, N) recombinantly expressing gwCryla-GFP and gwCrylb-GFP fusion proteins showed that the gwCryla antibody detected the gwCryla-GFP protein (Fig. 1O-Q), but not the gwCrylb-GFP protein (Fig. 1K-M). Together, all controls indicate that the gwCryla antibody specifically recognises the Cryla protein.

To exclude that the inconsistent Cryla localisation signals are due to methodological reasons, we tested the polyclonal Cryla antibody from Nießner and colleagues (Nießner et al. 2011, 2013), here 
named the "Cryla-Frankfurt antibody", of which a small amount was kindly provided by Nießner, with our own immunohistochemical protocol on European robin retinal sections (Fig. 2A). By doublestaining with the human blue opsin antibody OPN1SW-N20 (see Table 1), which specifically recognises the avian UV/V cone opsins (Nießner et al. 2011), we confirmed the UV/V cone outer segment localisation of Cryla. Moreover, we found the Cryla signal as a distinct punctate pattern throughout the whole length of the UV/V cone (Fig. 2B-E, green). When scanning single photoreceptor outer segments, we observed Cryla immunoreactivity in distinct spots inside the UV/V cone outer segments (Fig. 2D-E, green). The dots had an average diameter of $174 \mathrm{~nm}$. The UV/V opsin signal seemed to be most prominent on the borders so that the UV/V cone outer segment appeared hollow (Fig. 2D-E, magenta). In addition to the controls used by Nießner et al. (2011), we confirmed that the polyclonal Cryla-Frankfurt antibody detects erCryla-GFP (Fig. 2F-I) but not erCrylb-GFP fusion proteins (Fig. 2J-M) in transfected COS cells.

At this point in our study, we could not decipher which of the two antibodies was more reliable since both antibodies had passed all controls but showed contradictory Cryla localisation pattern when stained with fluorescent dyes. Therefore, we additionally generated a monoclonal antibody (mAb) (Cry1a-3E12) which specifically recognises the same peptide (aa 600-618) as the polyclonal antibody of Nießner et al. (2011) (Table 1). On retinal sections of nine European robin individuals (Fig. 3A), clone Cry1a-3E12 specifically labelled the UV/V cone outer segments (Fig. 3B-C, green). In four of them, the Cryla-3E12 staining showed a punctate pattern comparable to the one observed with the erCry1a-Frankfurt antibody (Fig. 2B-E, green). The spots appeared to be evenly distributed over the entire UV/V cone outer segment (Fig. 3E, green) and had an average diameter of $165 \mathrm{~nm}$. We observed the UV/V cone localisation and the spotted pattern in European robins sacrificed during migratory and non-migratory seasons and also on retinal sections of chickens (Fig. 4A-D) and Eurasian blackcaps (Sylvia atricapilla, Fig. 4E-H). For these experiments, we had to switch to a different antibody to detect the UV/V cone opsin staining (OPN1SW-P13), since the OPN1SW-N20 antibody was not available anymore. With OPN1SW-P13, we could not observe "hollow" outer segments as with the OPN1SW-N20 antibody before (Fig. 2D, E, magenta), but instead, the entire UV/V cone outer segment was stained (Fig. 3E, magenta). To test the specificity of the Cryla-3E12 
$\mathrm{mAb}$, we performed several experiments. After pre-adsorbing the antibody with the erCryla peptide, we obtained no Cryla signal on retinal sections (Fig. 3D). Immunocytochemistry on HEK cells expressing either erCry1a or erUVopsin as GFP fusion proteins revealed that Cry 1a-3E12 mAb recognised erCry1a-GFP (Fig. 3F-I) but not erUVopsin-GFP (see Fig. S2E-H in Supplemental Data). When pre-adsorbing the 3E12 mAb with the erCryla immunisation peptide (Fig. 3J-M) or omitting the primary antibody (Fig. S2A-D in Supplemental Data), we received no antibody signal. In immunoblots, Cry1 a-3E12 mAb detected a band of the expected size (96.2 kDa; erCry la protein 69.7 $\mathrm{kDa}$ and GFP protein tag $26.5 \mathrm{kDa}$ ) in samples of purified erCryla-GFP fusion protein (Fig. $3 \mathrm{~N})$. The Cry1a-3E12 antibody did not recognise any proteins in homogenates of HEK cells transfected with either erCrylb-GFP, erUVopsin-GFP, GFP, or un-transfected HEK cells. A band of the expected erCryla size of $69.7 \mathrm{kDa}$ was also detected in total retinal homogenates of the European robin (Fig. $3 \mathrm{~N}$ ) and the chicken (Fig. S2I in Supplemental Data). Taken together, all controls indicate that the monoclonal antibody Cry1a-3E12 specifically detects Cryla protein in the UV/V cones, confirming the Cryla localisation as observed by Nießner and colleagues (Nießner et al. 2011, 2013).

By means of fluorescence staining with the Cry1a-3E12 antibody, we confirmed that Cryla is localised in UV/V cones in the non-migratory domestic chicken (Fig. 4A-D), as reported by Nießner and colleagues (Nießner et al. 2011, 2013), and we additionally showed that Cryla is also located in the UV/V cones of a long-distance migratory songbird, the Eurasian blackcap (Fig. 4E-H). Next we tested whether we could confirm the strong differences in Cryla staining intensity between light- and dark-adapted bird retinae as claimed by Nießner and colleagues (Nießner et al. 2013). We labelled whole-mounted chicken and European robin retinae from birds that were previously light- or darkadapted for at least 30 min according to the protocol from Nießner et al. $(2013,2014,2018)$. In both light- and dark-adapted retinae from domestic chicken (Fig. 5A-I) and the European robin (Fig. 5J-O), Cryla immunoreactivity (Fig. 5, green) and UV/V opsin immunoreactivity (Fig. 5, magenta) were found exclusively in the outer segments of UV/V cones. We observed no striking differences in Cry1a staining intensities between the retinae of light-exposed chickens (Fig. 5A-C) and dark-adapted chickens (Fig. 5D-I) or between light-exposed robins (Fig. 5J-L) and dark-adapted robins (Fig. 5M-O). Furthermore, the vertical sections of European robin retinae stained with the original antibody from 
Nießner (Fig. 2B-E) originated from a dark-adapted robin for which Nießner claimed that there should be no or only a very weak Cryla immunosignal.

\section{DISCUSSION}

In research on magnetic sensing, many findings have turned out to be difficult to replicate (Mouritsen \& Hore 2012; Treiber et al. 2012; Ramirez et al. 2014; Engels et al. 2018). Immunohistochemical stainings on migratory birds are especially difficult to verify since knock-out animals as ultimate controls are not available. An alternative approach to confirm the labelling is to compare the staining patterns of different antibodies raised against different epitopes of the same target molecule (Burry 2000; Fritschy 2008). In the case of Cry 1a, it is difficult to use more than two different sequences since the Cryla isoform only differs from Crylb in 57 amino acids at the C-terminus. Here, we used three antibodies raised against two different peptide sequences and performed all the controls needed in accordance with the guidelines for proper controls in immunohistochemistry (Burry 2000; Uhlen et al. 2016). All antibodies showed labelling of photoreceptor outer segments (Figs 1G, 2B-E, 3B-E). Two antibodies [Cryla-3E12 mAb and Cryla-Frankfurt (Nießner et al. 2011)] confirmed immunoreactivity of Cryla in UV/V outer segments in double stainings as shown by Nießner et al. (2011). In addition to confirming Cryla expression in the outer segments of UV/V cones in the European robin (Erithacus rubecula, Figs 2A-E, 3A-E, 5) and the domestic chicken (Gallus gallus domesticus, Figs 4A-D, 5), we also observed Cry la at the same location in the Eurasian blackcap (Sylvia atricapilla, Fig. 4E-H). Furthermore, DAB stainings with the gwCryla antibody suggest a similar localisation in the domestic pigeon (Columba livia domestica, Fig. S1A-D in Supplemental Data) and the zebra finch (Taeniopygia guttata, Fig. S1E-H in Supplemental Data). Thus, the observed Cryla localisation in the outer segments of UV/V cones seems to be conserved over a wide range of bird species: from non-migratory species (chicken, zebra finch), to homing pigeons and a partiallymigratory middle-distance migrant (European robin) to a true long-distance migrant (Eurasian blackcap).

With two of the Cryla antibodies, we found Cryla immunoreactivity reproducibly and consistently accumulated in distinct dots in the outer segments of UV/V cones of European robin (Figs 2A-E, 3A- 
E) and chicken (Fig. 4A-D). With an average diameter of $174 \mathrm{~nm}$ (antibody Cry1a-Frankfurt, Nießner et al. 2011) and $165 \mathrm{~nm}$ (antibody Cry1a-3E12), these Cry1a-containing dots were very large in comparison to the $16 \mathrm{~nm}$ distance between two neighbouring outer segment membrane invaginations (Gunkel et al. 2015). Since no structures of the suggested size have so far been detected in the photoreceptor outer segments of birds, we do not dare to speculate about any significance of these dots at this moment.

In stainings of whole-mounted retinae from the domestic chicken and the European robin, we did not see notable differences in Cryla antibody signal intensities between light and dark-adapted retinae (Fig. 5). In contrast, Nießner et al. (2013) reported strong Cryla staining intensities in chicken retinae after exposure to sunlight and very weak staining after exposure to darkness. They also reported different Cryla staining intensities between retinae after exposure to different wavelengths (Nießner et al. 2014, 2018). They interpreted these results as evidence that their antibody only recognised a lightactivated form of Cryla, reflecting the FAD photocycle inside the protein and, therefore, demonstrating that FAD is bound to Cryla in vivo. Our results are inconsistent with the results and interpretations of Nießner et al. (2013, 2014, 2018) for the following reasons.

First, we did not observe any striking differences in Cryla staining intensities between light-exposed and dark-adapted whole-mounted chicken retinae (Fig. 5). Moreover, we found strong Cry la immunoreactivity in vertical sections of a dark-adapted European robin retina (Fig. 2B-E) stained with the original antibody from Nießner et al. $(2011,2013,2014,2018)$ and in a whole-mounted retina from a dark-adapted European robin stained with our monoclonal Cry1a-3E12 antibody (Fig. 5).

Second, in general, measuring absolute intensities in confocal microscopy and relating those intensities to differences in the amount of protein present is fraught with difficulties. Staining intensities depend on many factors, ranging from optical parameters to selection bias to properties of the dyes and of the biological samples, such as the presence of different amounts of pigment epithelium, small residual amounts of vitreous on top of the retina, and $\mathrm{pH}$-dependence of dyepenetration, all of which can vary locally during a staining (Pawley 2000; North 2006; Jonkman 2020). Keeping all parameters constant is even more of a problem with large, inherently 
inhomogeneous specimens like the chicken or robin retina (area $>1 \mathrm{~cm}^{2}$ ). Thus, in our experience, in any stained whole-mounted retina, one will be able to find patches with different staining intensities (see also Fig. S3 in Supplemental Data). Nießner et al. (2013) also acknowledged some inhomogeneity by stating "commonly, a thin layer of pigment epithelium remained attached to the retina". This thin layer was bleached "in order to make the retinae transparent for microscopy". However, it seems unlikely that bleached areas with and without pigment epithelium show the same antibody penetration and thus fluorescence intensity. Maybe this is also the reason why Nießner et al. $(2013,2014,2018)$ did not quantify the differences in fluorescence intensity but merely relied on qualitative assessments. At this point, we would like to briefly readdress a previous study by Liedvogel et al. (2007). In this study, we reported transient absorption measurements on a sample of garden warbler Cryla containing the FAD chromophore. Although the UV-visible spectrum showed evidence of the vibronic structure at $470 \mathrm{~nm}$ that is characteristic of correctly bound FAD (Liedvogel et al. 2007), this feature was not as prominent as it is for other cryptochromes that bind FAD strongly (Liu et al. 2010; Maeda et al. 2012; Kutta et al. 2017; Zoltowski et al. 2019; Otsuka et al. 2020). Despite strenuous attempts over the last 12 years, we have not been able to successfully replicate this expression and purification protocol to obtain a similar FAD-containing sample of a migratory bird Cryla. We therefore suspect that, by chance, the protein studied by Liedvogel et al. (2007) contained FAD in a kinetically trapped, but thermodynamically unstable position and that the protein was not properly folded around the chromophore, which could account for the less-than-obvious absorption at $470 \mathrm{~nm}$. Therefore, considering all our current knowledge, we do not think that the Liedvogel et al. (2007) data provide strong evidence for a thermodynamically stable Cryla-FAD complex. Kutta et al. (2017) calculated that $<3 \%$ of gwCryla could have FAD bound $\left(K_{\mathrm{D}}=97 \mu \mathrm{M}\right.$, typical FAD concentration in cells: 100 $\mathrm{nM}$ to $3 \mu \mathrm{M})$.

In summary, considering the results of our present study, we think that there is no conclusive evidence showing that an antibody directed against the C-terminal end of Cryla labels only a light-activated form of the Cryla protein. Consequently, in our view, immunohistochemical staining with Cryla antibodies cannot be used to study the FAD photocycle inside the protein, nor do the Nießner et al. 
$(2011,2013,2014,2018)$ studies show that FAD is bound to Cry 1a in vivo. Moreover, in vitro studies suggest that Cryla is unlikely to bind FAD under physiological conditions (Kutta et al. 2017, Wang et al. 2018).

If migratory bird Cryla does not bind FAD, Cryla cannot act as the primary magnetoreceptor molecule because, without the FAD, there can be no light-induced radical pairs and no magnetic field effects (Ritz et al. 2000, 2009; Mouritsen \& Hore 2012; Engels et al. 2014; Hore \& Mouritsen 2016). Since there are several reports that Cry4 from zebrafish (Ozturk et al. 2009), pigeon (Qin et al. 2016; Zoltowski et al. 2019; Hochstoeger et al. 2020), chicken (Otsuka et al. 2020) and European robin (Xu et al. unpublished data) can be expressed and purified with stoichiometric amounts of FAD bound, this seems to favour avian Cry4 (Cry4a and/or Cry4b; Einwich et al. 2020) over avian Cryla as the most suitable candidate primary receptor molecule for light-dependent magnetoreception in birds. Furthermore, there are no indications that Cry4 operates as a clock protein (Helfer et al. 2006; Ozturk et al. 2009; Günther et al. 2018; Pinzon-Rodriguez et al. 2018), Cry4 has only been found in animal classes that show magnetoreceptive behaviour (Günther et al. 2018; Kobayashi et al. 2000; Kubo et al. 2006; Takeuchi et al. 2014; Liu et al. 2015), and the localisation of Cry4 in the outer segments of double cones and long-wavelength single cones in night-migratory songbirds might allow for a particularly straightforward separation of light and magnetic field effects (Hore \& Mouritsen 2016; Worster et al. 2017; Günther et al. 2018).

However, since it is virtually impossible to definitively prove the absence of FAD binding in vivo, we cannot "exclude" that Cryla might be a magnetoreceptor molecule. If migratory bird Cryla were conclusively shown to bind FAD in vitro or in vivo inside a night-migratory bird, the presence of Cryla in short-wavelength, light sensitive UV/V-cones could be of particular interest for magnetic orientation. UV/V cones constitute the only cone type that does not contain oil droplets acting as longpass filters and thus cutting off short-wavelength light (Hart \& Vorobyev 2005; Hunt et al. 2009; Stavenga \& Wilts 2014). This might be important for magnetic orientation for two reasons: cryptochromes containing fully oxidised FAD absorb light in the blue wavelength range (Cashmore et al. 1999), and migratory birds seem well oriented from $372 \mathrm{~nm}$ (UV) to $565 \mathrm{~nm}$ (green) light, whereas 
they are less well-oriented under yellow or red light (Wiltschko et al. 1993, 2010; Wiltschko \& Wiltschko 1995b; Muheim et al. 2002). Furthermore, the cytoplasmic outer segment location of Cry1a rather speaks against a role as a classical circadian clock protein, since clock proteins act as transcription factors in the nucleus (Thresher et al. 1998; Kume et al. 1999; Liu et al. 2012).

In conclusion, the location of Cryla in UV/V cone outer segments could be suitable for a possible role as a blue-light sensor in magnetoreception, but, in our view, antibody stainings are neither suitable to demonstrate the presence of FAD in Cryla in vivo nor to study any magnetoreception-relevant photocycle of Cry1a.

\section{ACKNOWLEDGEMENTS}

We thank Christine Nießner for providing an aliquot of the original Frankfurt antibody used in Nießner et al. (2011). We thank Margrit Kanje, Irina Fomins, Jessica Schmidt and Bianca Brüggen for excellent technical support in the lab. The authors cordially acknowledge the Service Unit (Core Facility) Fluorescence Microscopy of the Carl-von-Ossietzky-University Oldenburg for the use of the imaging facilities.

\section{DISCLOSURE STATEMENT}

No potential conflict of interest was reported by the authors.

\section{FUNDING}

This project was funded by a Lichtenberg Professorship from the Volkswagen Stiftung to H.

Mouritsen by the Niedersächsisches Ministerium für Wissenschaft und Kultur to H. Mouritsen, by the Deutsche Forschungsgemeinschaft (RTG 1885/1-2: Molecular Basis of Sensory Biology to U. Janssen-Bienhold, A. Einwick, P.K. Seth, K. Dedek and H. Mouritsen; HE6221/1-1 to D. Heyers; MO 1408/1-2 to H. Mouritsen; SFB 1372: Magnetoreception and Navigation in Vertebrates to K. Dedek, 
D. Heyers and H. Mouritsen), by an ERC Synergy Grant no. 810002 ('QuantumBirds') to P.J. Hore and H. Mouritsen, by DARPA (QuBE N66001-10-1-4061) to H. Mouritsen and P.J. Hore, and by the Air Force Office of Scientific Research (Air Force Materiel Command USAF award FA9550-14-10095 to H. Mouritsen and P.J. Hore).

\section{ETHICAL STANDARD}

All animal procedures were performed in accordance with local, national, and EU guidelines for the use of animals in research and were approved by the Animal Care and Use Committees of the Niedersächsisches Landesamt für Verbraucherschutz und Lebensmittelsicherheit (LAVES, Oldenburg, Germany), Az: 3314-42502-04-10/0121.

\section{AUTHOR CONTRIBUTIONS}

P. Bolte and A. Einwick contributed equally to this work.

P. Bolte, K. Dedek and H. Mouritsen designed and supervised the experiments, A. Einwick, I.

Wojahn, P. Bolte, P.K. Seth, R. Chetverikova, D. Heyers and U. Janssen-Bienhold performed the experiments, P. Bolte, A. Einwick and H. Mouritsen analysed the data, R. Feederle generated monoclonal antibodies, P. Bolte, A. Einwick, K. Dedek, P.J. Hore and H. Mouritsen wrote the paper. All authors commented on the final manuscript.

\section{REFERENCES}

Bailey MJ, Chong NW, Xiong J, Cassone VM. 2002. Chicken's Cry2: molecular analysis of an avian cryptochrome in retinal and pineal photoreceptors. FEBS Lett. 513:169-174. 
Biskup T, Schleicher E, Okafuji A, Link G, Hitomi K, Getzoff ED, Weber S. 2009. Direct observation of a photoinduced radical pair in a cryptochrome blue-light photoreceptor. Angew Chem Int Ed. 48:404-407.

Bolte P, Bleibaum F, Einwich A, Günther A, Liedvogel M, Heyers D, Depping A, Wöhlbrand L, Rabus R, Janssen-Bienhold U, Mouritsen H. 2016. Localisation of the putative magnetoreceptor cryptochrome $1 \mathrm{~b}$ in the retinae of migratory birds and homing pigeons. PLoS ONE. 11:e0147819.

Burry RW. 2000. Specificity controls for immunocytochemical methods. J Histochem Cytochem. 48:163-166.

Cashmore A, Jarillo J, Wu Y, Liu D. 1999. Cryptochromes: blue light receptors for plants and animals. Science. 284:760-765.

Cochran WW, Mouritsen H, Wikelski M. 2004. Migrating songbirds recalibrate their magnetic compass daily from twilight cues. Science. 304:405-408.

Einwich A, Dedek K, Seth PK, Laubinger S, Mouritsen H. 2020. A novel isoform of cryptochrome 4 (Cry4b) is expressed in the retina of a night-migratory songbird. Sci Rep. 10(1):15794.

Engels S, Hein CM, Lefeldt N, Prior H, Mouritsen H. 2012. Night-migratory songbirds possess a magnetic compass in both eyes. PLoS ONE. 7(9):e43271.

Engels S, Schneider NL, Lefeldt N, Hein CM, Zapka M, Michalik A, Elbers D, Kittel A, Hore PJ, Mouritsen H. 2014. Anthropogenic electromagnetic noise disrupts magnetic compass orientation in a migratory bird. Nature. 509:353-356. 
Engels S, Treiber CD, Salzer MC, Michalik A, Ushakova L, Keays DA, Mouritsen H, Heyers D. 2018. Lidocaine is a nocebo treatment for trigeminally mediated magnetic orientation in birds. J R Soc Interface. 15:20180124.

Fritschy JM. 2008. Is my antibody-staining specific? How to deal with pitfalls of immunohistochemistry. Eur J Neurosci. 12:2365-2370.

Günther A, Einwich A, Sjulstok E, Feederle R, Bolte P, Koch KW, Solov'yov I, Mouritsen H. 2018. Double-cone localization and seasonal expression pattern suggest a role in magnetoreception for European robin cryptochrome 4. Curr Biol. 28(2):211-223.

Gunkel M, Schöneberg J, Alkhaldi W, Irsen S, Noé F, Kaupp UB, Al-Amoudi A. 2015. Higher-order architecture of rhodopsin in intact photoreceptors and its implication for phototransduction kinetics. Structure. 23(4):628-638.

Hart NS, Vorobyev M. 2005. Modelling oil droplet absorption spectra and spectral sensitivities of bird cone photoreceptors. J Comp Physiol A. 191:381-392.

Hein CM, Engels S, Kishkinev D, Mouritsen H. 2011. Robins have a magnetic compass in both eyes. Nature. 471:E11-E12.

Hein CM, Zapka M, Heyers D, Kutzschbauch S, Schneider N-L, Mouritsen H. 2010. Night-migratory garden warblers can orient with their magnetic compass using the left, the right or both eyes. J R Soc Interface. 7:227-233.

Helfer G, Fidler AE, Vallone D, Foulkes NS, Brandstaetter R. 2006. Molecular analysis of clock gene expression in the avian brain. Chronobiol Int. 23:113-127. 
Heyers D, Manns M, Luksch H, Güntürkün O, Mouritsen H. 2007. A visual pathway links brain structures active during magnetic compass orientation in migratory birds. PLoS ONE. 2(9):e937.

Heyers D, Manns M, Luksch H, Güntürkün O, Mouritsen H. 2008. Calcium-binding proteins label functional streams of the visual system in a songbird. Brain Res Bull. 75:348-355.

Hiscock HG, Worster S, Kattnig DR, Steers C, Jin Y, Manolopoulos DE, Mouritsen H, Hore PJ. 2016. The quantum needle of the avian magnetic compass. Proc Natl Acad Sci USA. 113:4634-4639.

Hochstoeger T, Said TA, Maestre D, Walter F, Vilceanu A, Pedron M, Cushion TD, Snider W, Nimpf S, Nordmann GC, et al. 2020. The biophysical, molecular, and anatomical landscape of pigeon CRY4: A candidate light-based quantal magnetosensor. Sci Adv. 6(33):eabb9110.

Hore PJ, Mouritsen H. 2016. The radical-pair mechanism of magnetoreception. Annu Rev Biophys. 45:299-344.

Hsu DS, Zhao X, Zhao S, Kazantsev A, Wang RP, Todo T, Wie YF, Sancar A. 1996. Putative human blue-light photoreceptors hCRY1and hCRY2 are flavoproteins. Biochem. 35:13871-13877.

Hunt DM, Carvalho LS, Cowing JA, Davies WL. 2009. Evolution and spectral tuning of visual pigments in birds and mammals. Phil Trans R Soc Lond B. 364:2941-2955.

Jonkman J. 2020. Rigor and reproducibility in confocal fluorescence microscopy. Cytometry A. 97:113-115.

Kobayashi Y, Ishikawa T, Hirayama J, Daiyasu H, Kanai S, Toh H, Fukuda I, Tsujimura T, Terada N, Kamei Y, et al. 2000. Molecular analysis of zebrafish photolyase/cryptochrome family: Two types of cryptochromes present in zebrafish. Genes Cells. 5:725-738. 
Kobylkov D, Schwarze S, Michalik B, Winklhofer M, Mouritsen H, Heyers D. 2020. A newly identified trigeminal brain pathway in a night-migratory bird could be dedicated to transmitting magnetic map information. Proc R Soc Lond B. 287:20192788.

Kranz K, Dorgau B, Pottek M, Herrling R, Schultz K, Bolte P, Monyer H, Penuela S, Laird DW, Dedek K, et al. 2013. Expression of Pannexin1 in the outer plexiform layer of the mouse retina and physiological impact of its knockout. J Comp Neurol. 521(5):1119-1135.

Kubo Y, Akiyama M, Fukada Y, Okano T. 2006. Molecular cloning, mRNA expression, and immunocytochemical localization of a putative blue-light photoreceptor CRY4 in the chicken pineal gland. J Neurochem. 97:1155-1165.

Kume K, Zylka MJ, Sriram S, Shearman LP, Weaver DR, Jin X, Maywood MH, Reppert SM. 1999. mCRY1 and mCRY2 are essential components of the negative limb of the circadian clock feedback loop. Cell. 98:193-205.

Kutta RJ, Archipowa N, Johannissen LO, Jones AR, Scrutton NS. 2017. Vertebrate cryptochromes are vestigial flavoproteins. Sci Rep. 7:44906.

Lee AA, Lau JCS, Hogben HJ, Biskup T, Kattnig TDR, Hore PJ. 2014. Alternative radical pairs for cryptochrome-based magnetoreception. J R Soc Interface. 11:20131063.

Liedvogel M, Maeda K, Henbest K, Schleicher E, Simon T, Timmel CR, Hore PJ, Mouritsen H. 2007. Chemical magnetoreception: bird cryptochrome 1a is excited by blue light and forms long-lived radical-pairs. PLoS ONE. 2(10):e1106. 
Liedvogel M, Mouritsen H. 2009. Cryptochromes - a potential magnetoreceptor: what do we know and what do we want to know? J R Soc Interface. 7:147-162.

Liu B, Liu H, Zhong D, Lin C. 2010. Searching for a photocycle of the cryptochrome photoreceptors. Curr Opin Plant Biol. 13:578-586.

Liu C, Hu J, Qu C, Wang L, Huang G, Pengfei N, Zhong Z, Hong F, Wang G, Postlethwait JH, Wang H. 2015. Molecular evolution and functional divergence of zebrafish (Danio rerio) cryptochrome genes. Sci Rep. 5:8113.

Liu X, Zhang Z, Ribelayga CP. 2012. Heterogeneous expression of the core circadian clock proteins among neuronal cell types in mouse retina. PLoS ONE. 7:e50602.

Maeda K, Henbest KB, Cintolesi F, Kuprov I, Rodgers CT, Liddell PA, Gust D, Timmel CR, Hore PJ. 2008. Chemical compass model of avian magnetoreception. Nature. 453:387-390.

Maeda K, Robinson AJ, Henbest KB, Hogben HJ, Biskup T, Ahmad M, Schleicher E, Weber S, Timmel CR, Hore PJ. 2012. Magnetically sensitive light-induced reactions in cryptochrome are consistent with its proposed role as a magnetoreceptor. Proc Natl Acad Sci USA. 109(13):4774-4779.

Möller A, Sagasser S, Wiltschko W, Schierwater B. 2004. Retinal cryptochrome in a migratory passerine bird: a possible transducer for the avian magnetic compass. Naturwissenschaften. 91:585588.

Mouritsen H. 2013. The magnetic senses. In: Galizia CG, Lledo PM, editors. Neurosciences: From molecule to behavior: a university textbook. Berlin: Springer; p. 427-443. 
Mouritsen H. 2018. Long-distance navigation and magnetoreception in migratory animals. Nature. $558: 50-59$

Mouritsen H, Heyers D, Güntürkün O. 2016. The neural basis of long-distance navigation in birds. Annu Rev Physiol. 78:133-154.

Mouritsen H, Hore PJ. 2012. The magnetic retina: light-dependent and trigeminal magnetoreception in migratory birds. Curr Opin Neurobiol. 22:343-352.

Muheim R, Backman J, Akesson S. 2002. Magnetic compass orientation in European robins is dependent on both wavelength and intensity of light. J Exp Biol. 205:3845-3856.

Neuhoff V, Philipp K, Zimmer HG, Mesecke SA. 1979. A simple, versatile, sensitive and volumeindependent method for quantitative protein determination which is independent of other external influences. Hoppe-Seyler's Z Physiol Chem. 360:1657-1670.

Nießner C, Denzau S, Gross JC, Peichl L, Bischof HJ, Fleissner G, Wiltschko W, Wiltschko R. 2011. Avian ultraviolet/violet cones identified as probable magnetoreceptors. PLoS ONE. 6:e20091.

Nießner C, Denzau S, Peichl L, Wiltschko W, Wiltschko R. 2014. Magnetoreception in birds: Immunohistochemical studies concerning the cryptochrome cycle. J Exp Biol. 217:4221-4224.

Nießner C, Denzau S, Peichl L, Wiltschko W, Wiltschko R. 2018. Magnetoreception: activation of avian cryptochrome 1a in various light conditions. J Comp Physiol A. 204:977-984.

Nießner C, Denzau S, Stapput K, Ahmad M, Peichl L, Wiltschko W, Wiltschko R. 2013. Magnetoreception: Activated Cryptochrome 1a concurs with magnetic orientation in birds. J R Soc Interface. 10:20130638. 


\begin{abstract}
Nießner C, Gross JC, Denzau S, Peichl L, Fleissner G, Wiltschko W, Wiltschko R. 2016. Seasonally changing cryptochrome $1 \mathrm{~b}$ expression the retinal ganglion cells of a migrating passerine bird. PLoS ONE. 11:e0150377.
\end{abstract}

North AJ. 2006. Seeing is believing? A beginners' guide to practical pitfalls in image acquisition. J Cell Biol. 172:9-18.

Otsuka H, Mitsui H, Miura K, Okano K, Imamoto Y, Okano T. 2020. Rapid oxidation following photoreduction in the avian cryptochrome4 photocycle. Biochemistry. 59:3615-3625.

Ozturk N, Selby CP, Song SH, Ye R, Tan C, Kao YT, Zhong D, Sancar A. 2009. Comparative photochemistry of animal type 1 and type 4 cryptochromes. Biochemistry. 48(36):8585-8593.

Ozturk N, Song SH, Ozgür S, Selby CP, Morrison L, Partch C, Zhong D, Sancar A. 2007. Structure and function of animal cryptochromes. Cold Spring Harb Symp Quant Biol. 72:119-131.

Pawley J. 2000. The 39 steps: A cautionary tale of quantitative 3-D fluorescence microscopy. Biotechniques. 28(5):884-886.

Pinzon-Rodriguez A, Bensch S, Muheim R. 2018. Expression patterns of cryptochrome genes in avian retina suggest involvement of Cry4 in light-dependent magnetoreception. J R Soc Interface. 15:20180058.

Qin S, Yin H, Yang C, Dou Y, Liu Z, Zhang P, Yu H, Huang Y, Feng J, Hao J, et al. 2016. A magnetic protein biocompass. Nat Mater. 15(2):217-226. 
Ramírez E, Marín G, Mpodozis J, Letelier JC. 2014. Extracellular recordings reveal absence of magneto sensitive units in the avian optic tectum. J Comp Physiol A. 200(12):983-996.

Ritz T, Adem S, Schulten K. 2000. A model for photoreceptor-based magnetoreception in birds. Biophys J. 78:707-718.

Ritz T, Thalau P, Phillips JB, Wiltschko R, Wiltschko W. 2004. Resonance effects indicate a radicalpair mechanism for avian magnetic compass. Nature. 429:177-180.

Ritz T, Wiltschko R, Hore PJ, Rodgers CT, Stapput K, Thalau P, Timmel CR, Wiltschko W. 2009. Magnetic compass of birds is based on a molecule with optimal directional sensitivity. Biophys J. 96:3451-3457.

Rodgers CT, Hore P. 2009. Chemical magnetoreception in birds: the radical pair mechanism. Proc Natl Acad Sci USA. 106:353-360.

Sancar A. 2000. Cryptochrome: the second photoactive pigment in the eye and its role in circadian photoreception. Annu Rev Biochem. 69:31-67.

Sancar A. 2004. Regulation of the mammalian circadian clock by cryptochromes. J Biol Chem. 279:34079-34082.

Schulten K, Swenberg CE, Weller AA. 1978. A biomagnetic sensory mechanism based on magnetic field modulated coherent electron spin motion. Z Phys Chem. 111:1-5.

Schwarze S, Schneider NL, Reichl T, Dreyer D, Lefeldt N, Engels S, Baker N, Hore PJ, Mouritsen M. 2016. Weak broadband electromagnetic fields are more disruptive to magnetic compass orientation in 
a night-migratory songbird (Erithacus rubecula) than strong narrow-band fields. Front Behav Neurosci. 10:55.

Shu S, Ju G, Fan L. 1988. The glucose-oxidase-DAB-nickel method in peroxidase histochemistry of the nervous system. Neurosci Lett. 85:169-171.

Solov'yov IA, Mouritsen H, Schulten K. 2010. Acuity of a cryptochrome and vision-based magnetoreception system in birds. Biophys J. 99:40-49.

Solov'yov IA, Ritz T, Schulten K, Hore PJ. 2014. A chemical compass for bird navigation. In: Mohseni M, et al., editors. Quantum effects in biology. Cambridge: Cambridge University Press; p. $218-236$.

Stavenga DG, Wilts BD. 2014. Oil droplets of bird eyes: microlenses acting as spectral filters. Phil Trans R Soc Lond B. 369:20130041.

Takeuchi T, Kubo Y, Okano K, Okano T. 2014. Identification and characterization of cryptochrome4 in the ovary of western clawed frog Xenopus tropicalis. Zool Sci. 31:152-159.

Thresher RJ, Vitaterna MH, Miyamoto Y, Kazantsev A, Hsu DS, Petit C, Selby CP, Dawut L, Smithies O, Takahashi JS, Sancar A. 1998. Role of mouse cryptochrome blue-light photoreceptor in circadian photoresponses. Science. 282:1490-1494.

Treiber CD, Salzer MC, Riegler J, Edelman N, Sugar C, Breuss M, Pichler P, Cadiou H, Saunders M, Lythgoe M, et al. 2012. Clusters of iron-rich cells in the upper beak of pigeons are macrophages not magnetosensitive neurons. Nature. 484(7394):367-70. 
Uhlen M, Bandrowski A, Carr S, Edwards A, Ellenberg J, Lundberg E, Rimm DL, Rodriguez H, Hiltke T, Snyder M, Yamamoto T. 2016. A proposal for validation of antibodies. Nat Methods. 10:823-827.

Wang X, Chengyu J, Selby CP, Chiou YY, Yang Y, Wu W, Sancar A, Wang J. 2018. Comparative properties and functions of type 2 and type 4 pigeon cryptochromes. Cell Mol Life Sci. 75:4629-4641.

Wiltschko R, Stapput K, Thalau P, Wiltschko W. 2010. Directional orientation of birds by the magnetic field under different light conditions. J R Soc Interface. 7:163-177.

Wiltschko R, Wiltschko W. 1995a. Magnetic orientation in animals. Berlin, Springer.

Wiltschko W. 1968. Über den Einfluß statischer Magnetfelder auf die Zugorientierung der Rotkehlchen, Erithacus rubecula. [On the influence of static magnetic fields on the migration orientation of robins, Erithacus rubecula]. Z Tierpsychol. 25:537-558. German.

Wiltschko W, Munro U, Ford H, Wiltschko R. 1993. Red light disrupts magnetic orientation of migratory birds. Nature. 364:525-527.

Wiltschko W, Wiltschko R. 1972. Magnetic compass of European robins. Science. 176:62-64.

Wiltschko W, Wiltschko R. 1995b. Migratory orientation of European robins is affected by the wavelength of light as well as by a magnetic pulse. J Comp Physiol. 177:363-369.

Worster S, Mouritsen H, Hore PJ. 2017. A light-dependent magnetoreception mechanism insensitive to light intensity and polarization. J R Soc Interface. 14:20170405. 
Wu H, Scholten A, Einwich A, Mouritsen H, Koch K-W. 2020. Protein-protein interaction of the putative magnetoreceptor cryptochrome 4 expressed in the avian retina. Sci Rep. 10:7364.

Zapka M, Heyers D, Hein CM, Engels S, Schneider NL, Hans J, Weiler S, Dreyer D, Kishkinev D, Wild JM, Mouritsen H. 2009. Visual but not trigeminal mediation of magnetic compass information in a migratory bird. Nature. 461:1274-1277.

Zapka M, Heyers D, Liedvogel M, Jarvis ED, Mouritsen H. 2010. Night-time neuronal activation of Cluster $\mathrm{N}$ in a day- and night-migrating songbird. Eur J Neurosci. 32:619-624.

Zoltowski BD, Chelliah Y, Wickramaratne A, Jarocha L, Karki N, Xu W, Mouritsen H, Hore PJ, Hibbs RE, Green CB, Takahashi JS. 2019. Chemical and structural analysis of a photoactive vertebrate cryptochrome from pigeon. Proc Natl Acad Sci USA. 116(39):19449-19457. 


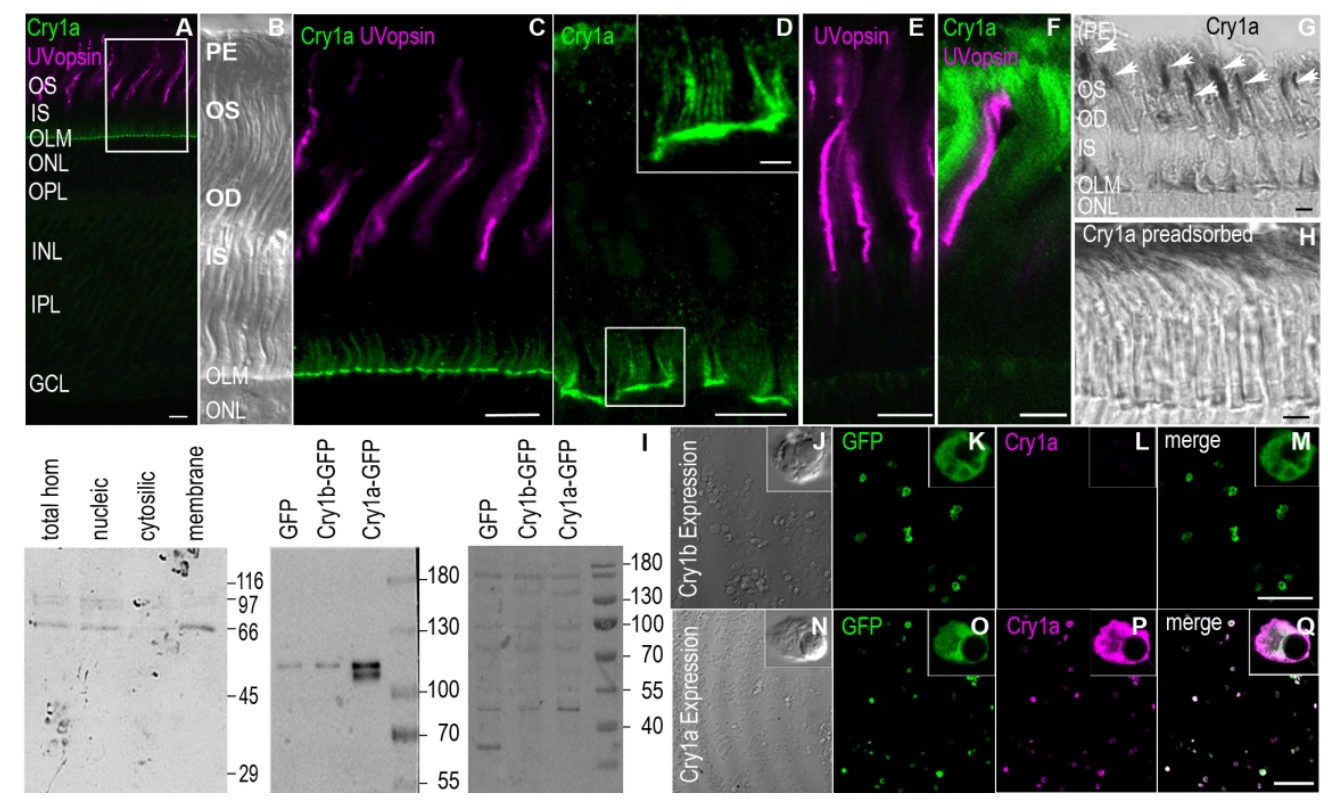

Fig. 1. The antibody gwCry1a labelled the outer limiting membrane in immunofluorescence but labelled outer segments with the DAB staining method. Immunohistochemical stainings of the European robin retina (A-F) with the gwCry1a antibody showed Cry1a expression (A, C, D, green) at or near the outer limiting membrane (OLM) when stained with fluorescent reporter molecules. As controls, the gwCry1a antibody was replaced by the pre-immune serum ( $E$, green) or blocked by the corresponding Cry1a peptide $(F$, green). The UV/V cone outer segments (OS) were visualised using the antibody OPN1SW-N20 ( $A, C, E, F$ magenta). When using the chromogenic DAB method (black staining), distinct photoreceptor outer segments in the European robin retina were stained with the gwCry1a antibody $(\mathrm{G})$ but not with the pre-immune serum $(\mathrm{H})$. In immunoblots, the Cry1a protein $(69.7 \mathrm{kDa})$ was present in total protein homogenate $(\mathrm{TH})$, the nucleic fraction ( $\mathrm{Nu}$ ), the cytosolic fraction (Cyt) and the membrane fraction (M) of the European robin retina (I, left immunoblot). Immunoblots on recombinantly expressed erCry1a-GFP fusion proteins (I, middle blot Cry1aGFP) incubated with the gwCry1a antibody showed two bands for the erCry1a-GFP fusion protein. The lower band exclusively occurred in lysates of erCry1a-GFP expressing cells (I, middle blot, Cry1a-GFP) but not in lysates of erCry1b-GFP (I, middle blot, Cry1b-GFP) and GFP expressing cells (I, middle blot, GFP). The Cry1a-GFP specific band was not detected in controls in which the gwCry1a antibody was replaced by preimmune serum (I, right blot). Staining of HEK cells (J, N) expressing either gwCry1b-GFP (J-M) or gwCry1aGFP protein (N-Q) with the gwCry1a antibody indicated that the antibody detected gwCry1a-GFP protein (P, $\mathrm{Q})$, but not gwCry1b-GFP protein $(\mathrm{L}, \mathrm{M})$. Images $A, C-F, K-M$ and $\mathrm{O}-\mathrm{Q}$ are maximum projections of confocal stacks $(A, C-F$ 6-8 $\mu \mathrm{m} ; \mathrm{K}-\mathrm{M}$ and $\mathrm{O}-\mathrm{Q} 1 \mu \mathrm{m})$ and were taken from the same experiment with identical microscope settings; $B, G, H, J, N$ are bright field images. Scale bars: A, C-F $10 \mu m$; Inset in D $2 \mu \mathrm{m}$; G, H 5 $\mu \mathrm{m} ; \mathrm{M}, \mathrm{Q} 100 \mu \mathrm{m}$. PE, pigment epithelium; OD, oil droplets; OLM, outer limiting membrane; ONL, outer nuclear layer; OPL, outer plexiform layer; INL, inner nuclear layer; IPL, inner plexiform layer; GCL, ganglion cell layer.

$170 \times 101 \mathrm{~mm}(300 \times 300 \mathrm{DPI})$ 


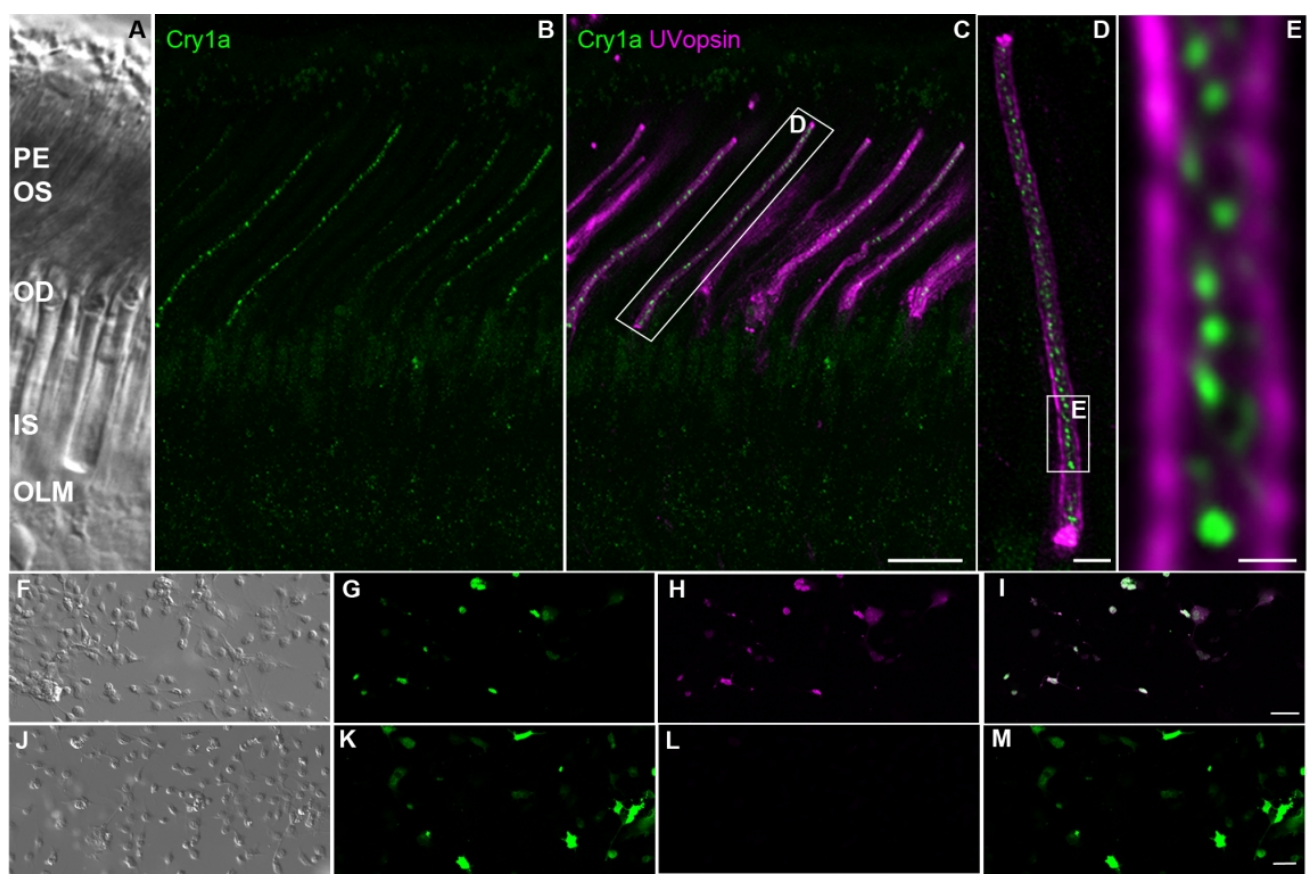

Fig. 2. The antibody Cry1a-Frankfurt from Nießner et al. (2011) showed Cry1a expression as a punctuate pattern in UV/V cone outer segments. Immunohistochemical staining of the European robin retina (A) with the Cry1a-Frankfurt antibody showed Cry1a expression (B, C, green) in OPN1SW-N20 labelled (C, magenta) UV/V cone outer segments. The Cry1a immunosignal showed a punctuate pattern throughout the entire outer segment (D, E, green). Staining of COS cells expressing erCry1a-GFP protein (F-I) or erCry1b-GFP protein $(\mathrm{J}-\mathrm{M})$ with the Cryla-Frankfurt antibody in magenta $(\mathrm{H}, \mathrm{L})$ indicated that the antibody detected the erCry1a-GFP $(H, I)$ but not the erCry1b-GFP protein ( $L, M)$. Confocal images (B-D) were maximum projections of confocal stacks subjected to deconvolution: B, C z-size $4.15 \mu \mathrm{m}, 10$ sections (containing the whole outer segment); D z-size $2.9 \mu \mathrm{m}, 10$ sections. $E$ is one single scan of $D$. Stacks of images B-D were subjected to deconvolution. Scale bars: C $10 \mu \mathrm{m}$; D $2 \mu \mathrm{m} ; \mathrm{E} 0.5 \mu \mathrm{m} ; \mathrm{I}, \mathrm{M} 50 \mu \mathrm{m}$. PE, pigment epithelium; OS, photoreceptor outer segments; OD, oil droplets; IS, photoreceptor inner segments; OLM, outer limiting membrane; ONL, outer nuclear layer.

$170 \times 112 \mathrm{~mm}(300 \times 300 \mathrm{DPI})$ 

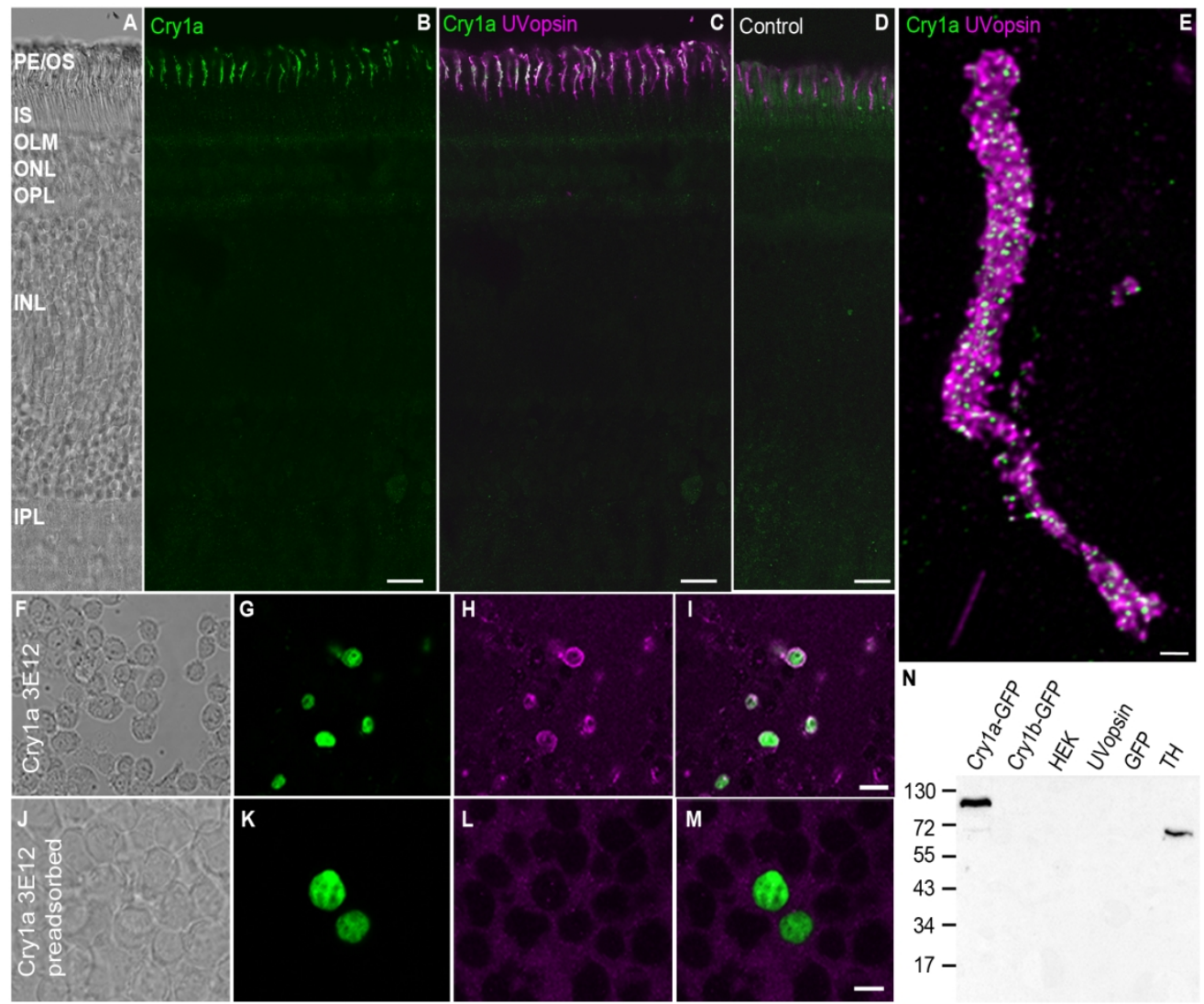

Fig. 3. The antibody Cry1a-3E12 confirmed Cry1a expression as punctuate pattern in UV/V cone outer segments. In immunohistochemical stainings of European robin retina (A) with the Cry 1 a-3E12 antibody, Cry1a expression ( $B, C$, green) was found to be localised in the same UV/V cone outer segments that were labelled with the antibody OPN1SW-N20 (C, magenta). As a control, binding of Cry1a-3E12 antibody was blocked by pre-incubation with the according Cry1a peptide (D). A closer look at the UV/V cone outer segments revealed a punctuate pattern of the Cry1a immunoreactivity throughout the entire outer segment associated with OPN1SW-P13 labelling $(E)$. Staining of HEK cells $(F, J)$ expressing erCry1a-GFP protein (F-M) with Cry1a-3E12 antibody $(H, I)$ or with pre-adsorbed Cry1a-3E12 antibody $(L, M)$ indicated that the antibody detected erCry1a-GFP protein $(H, I)$, whereas the pre-adsorption control was negative $(L, M)$. Immunoblots on recombinantly expressed erCry1a-GFP fusion proteins ( $N$, Cry1a-GFP) as well as protein homogenate from European robin retina $(\mathrm{N}, \mathrm{TH})$ incubated with the Cry1a-3E12 antibody showed bands of the expected size of $96.2 \mathrm{kDa}$ for the erCry1a-GFP fusion protein and $69.7 \mathrm{kDa}$ for the retinal proteins. The band was absent in protein samples of erCry1b-GFP expressing HEK cells (N, Cry1b-GFP), un-transfected HEK cells ( $N$, HEK), erUVopsin-GFP ( $N$, UVopsin) and GFP expressing HEK cells (N, GFP). Images A, F, J are bright field images. Images B-D were taken from the same experiment with identical microscope settings. Images B-E are maximum projections of confocal stacks (B-C z-size $5.20 \mu \mathrm{m}, 26$ sections; $\mathrm{D}$ z-size $5.28 \mu \mathrm{m}$, 28 sections; E $5.41 \mu \mathrm{m}, 43$ sections) and were subjected to deconvolution. Images G-I and K-M are single confocal scans. Scale bars: B, C, D $20 \mu \mathrm{m}$; I $20 \mu \mathrm{m} ;$ M $10 \mu \mathrm{m}$; E $1 \mu \mathrm{m}$. PE, pigment epithelium; OS, photoreceptor outer segments; IS, photoreceptor inner segments; OLM, outer limiting membrane; ONL, outer nuclear layer; OPL, outer plexiform layer; INL, inner nuclear layer; IPL, inner plexiform layer.

$170 \times 142 \mathrm{~mm}(300 \times 300 \mathrm{DPI})$ 


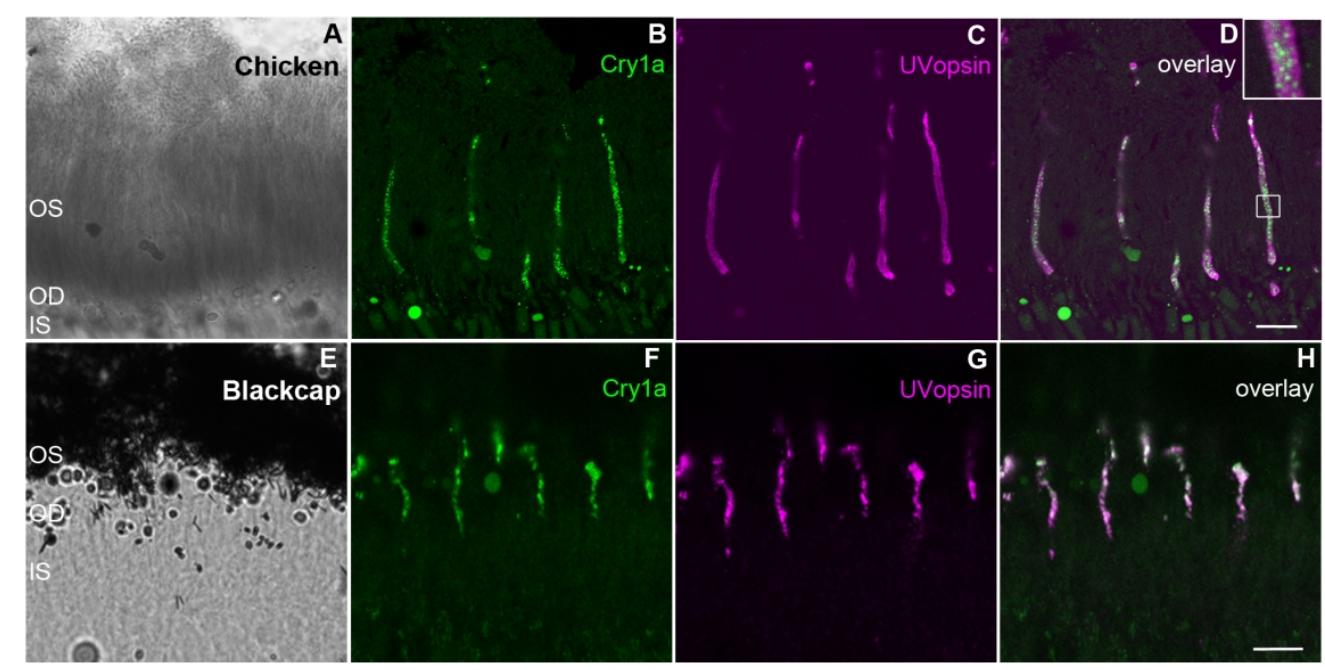

Fig. 4. UV/V cone outer segment localisation of Cry1a was confirmed in two additional bird species. The antibody Cry1a-3E12 showed a punctuate pattern in UV/V cone outer segments in chicken (A-D, UV/V opsin antibody OPN1SW-N20, magenta). In blackcap we also confirmed Cry1a-3E12 immuno-reactivity in UV/V cone outer segments (E-H, UV/V opsin antibody OPN1SW-P13, magenta). Images B-D are single confocal scans. Images F-H are maximum projections of confocal stacks (z-size $2.20 \mu \mathrm{m}, 16$ sections). All images for the respective species were taken from the same experiment with identical microscope settings. Scale bars:

D, H $10 \mu \mathrm{m}$. OS, photoreceptor outer segments; OD, oil droplets; IS, photoreceptor inner segments.

$170 \times 85 \mathrm{~mm}(300 \times 300 \mathrm{DPI})$ 


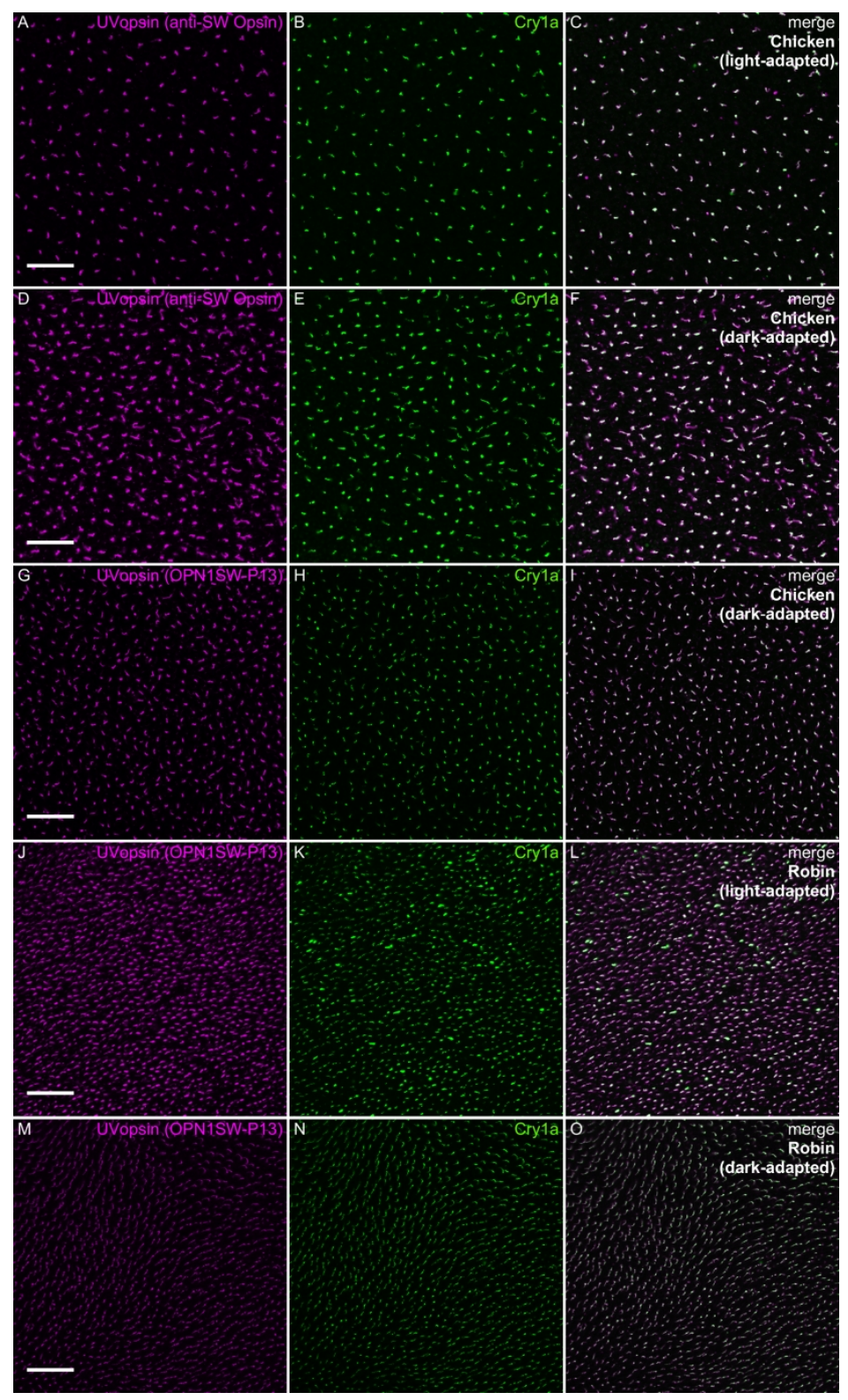

Fig. 5. The intensity of the Cry1a labelling did not differ in light-exposed versus dark-adapted birds. When staining whole-mounted retinae of both, the European robin and the domestic chicken, with the Cry1a-3E12 antibody (green) and the UV/V opsin antibody (magenta), we found immunoreactivity of both Cry1a and UV/V opsin exclusively in the outer segments of UV/V cones. The intensity of the Cry 1 a labelling was not considerably different between light-adapted chickens (A-C) and dark-adapted chickens (D-I). We also found strong Cry1a immunoreactivity in whole-mounted retinae from both a light-adapted (J-L) and a dark-adapted (M-O) European robin. All images were taken at the level of the outer segments, and the images of the respective species were taken from the same experiment with identical microscope settings. Shown are maximum projections of confocal stacks: 7 sections, step size $0.42 \mu \mathrm{m}$. Scale bars: $50 \mu \mathrm{m}$.

$$
209 \times 350 \mathrm{~mm}(300 \times 300 \mathrm{DPI})
$$




\begin{tabular}{|c|c|c|c|c|c|c|}
\hline Antibody & Immunogene & $\begin{array}{l}\text { Recognising } \\
\text { peptide }\end{array}$ & Source & Host & Type & $\begin{array}{l}\text { Dilution, } \\
\text { enhancing } \\
\text { antibody }\end{array}$ \\
\hline $\begin{array}{l}\text { gwCryla } \\
\text { (Serum 2) }\end{array}$ & $\begin{array}{l}25 \text { aa (565-589), C- } \\
\text { terminal end of the } \\
\text { garden } \\
\text { warbler/European } \\
\text { robin Cryla protein } \\
\text { sequence (GenBank } \\
\text { accession number } \\
\text { CAG14931) }\end{array}$ & $\begin{array}{l}\text { CQASSILHYA } \\
\text { HGDNQQSHL } \\
\text { LQAGRT }\end{array}$ & $\begin{array}{l}\text { this study; } \\
\text { custom-made } \\
\text { by Pineda } \\
\text { Antibody } \\
\text { Service, } \\
\text { Berlin, } \\
\text { Germany }\end{array}$ & rabbit & $\begin{array}{l}\text { polyclonal } \\
\text { (pc) }\end{array}$ & $1: 200$ \\
\hline $\begin{array}{l}\text { Cryla- } \\
\text { Frankfurt }\end{array}$ & $\begin{array}{l}20 \text { aa }(600-619), C- \\
\text { terminal end of the } \\
\text { garden } \\
\text { warbler/European } \\
\text { robin Cryla protein } \\
\text { sequence }\end{array}$ & \begin{tabular}{|l} 
RPNPEEETQS \\
VGPKVQRQS \\
T \\
\end{tabular} & $\begin{array}{l}\text { Nießner et al. } \\
2011\end{array}$ & $\begin{array}{l}\text { guinea } \\
\text { pig }\end{array}$ & $\mathrm{pc}$ & $1: 500$ \\
\hline Cryla-3E12 & $\begin{array}{l}21 \text { aa }(600-620), C- \\
\text { terminal end of the } \\
\text { garden } \\
\text { warbler/European } \\
\text { robin Cry1a protein } \\
\text { sequence }\end{array}$ & $\begin{array}{l}\text { RPNPEEETQS } \\
\text { VGPKVQRQS } \\
\text { TN }\end{array}$ & this study & rat & $\begin{array}{l}\text { monoclonal } \\
(\mathrm{mc})\end{array}$ & $\begin{array}{l}\text { undiluted, } \\
1: 2,1: 3 \\
1: 5, \operatorname{IgG} 1\end{array}$ \\
\hline $\begin{array}{l}\text { OPN1SW- } \\
\text { N20 }\end{array}$ & $\begin{array}{l}20 \text { aa }(8-27), \mathrm{N}- \\
\text { terminal epitope of the } \\
\text { human S (blue) cone } \\
\text { opsin }\end{array}$ & $\begin{array}{l}\text { EFYLFKNISS } \\
\text { VGPWDGPQY } \\
\text { H }\end{array}$ & $\begin{array}{l}\text { Santa Cruz } \\
\text { Biotech- } \\
\text { nology, } \\
\text { Dallas, TX, } \\
\text { USA; sc- } \\
14363\end{array}$ & goat & $\mathrm{pc}$ & $\begin{array}{l}1: 500 \text { or } \\
1: 1000\end{array}$ \\
\hline $\begin{array}{l}\text { OPN1SW- } \\
\text { P13 }\end{array}$ & $\begin{array}{l}\text { last } 40 \text { aa C-terminal } \\
\text { epitope of the human } \\
\text { S (blue) cone opsin }\end{array}$ & $\begin{array}{l}\text { QFQACIMKM } \\
\text { VCGKAMTDE } \\
\text { SDTCSSQKTE } \\
\text { VSTVSSTQV } \\
\text { GPN } \\
\end{array}$ & $\begin{array}{l}\text { Santa Cruz } \\
\text { Biotechno- } \\
\text { logy, sc- } \\
31628\end{array}$ & goat & $\mathrm{pc}$ & 1: 500 \\
\hline $\begin{array}{l}\text { anti-SW } \\
\text { Opsin } \\
\text { AB5407 }\end{array}$ & $\begin{array}{l}\text { human S (blue) cone } \\
\text { opsin }\end{array}$ & & $\begin{array}{l}\text { Merck } \\
\text { AB5407 }\end{array}$ & rabbit & $\mathrm{pc}$ & $1: 500$ \\
\hline $\begin{array}{l}\text { Rhodopsin } \\
\text { (Rho1D4) }\end{array}$ & Bovine rhodopsin & TETSQVAPA & \begin{tabular}{|l} 
Cell \\
Essentials, \\
Boston, MA, \\
USA \\
\end{tabular} & mouse & $\mathrm{mc}$ & $1: 500$ \\
\hline $\begin{array}{l}\text { BlueOpsin } \\
\text { (2D6) }\end{array}$ & $\begin{array}{l}\text { Blue sensitive cone } \\
\text { opsin from chicken }\end{array}$ & $\begin{array}{l}\text { MHPPRPTTD } \\
\text { LPEDF }\end{array}$ & $\begin{array}{l}\text { Günther et al. } \\
2018\end{array}$ & rat & $\mathrm{mc}$ & 1:3, IgG1 \\
\hline
\end{tabular}




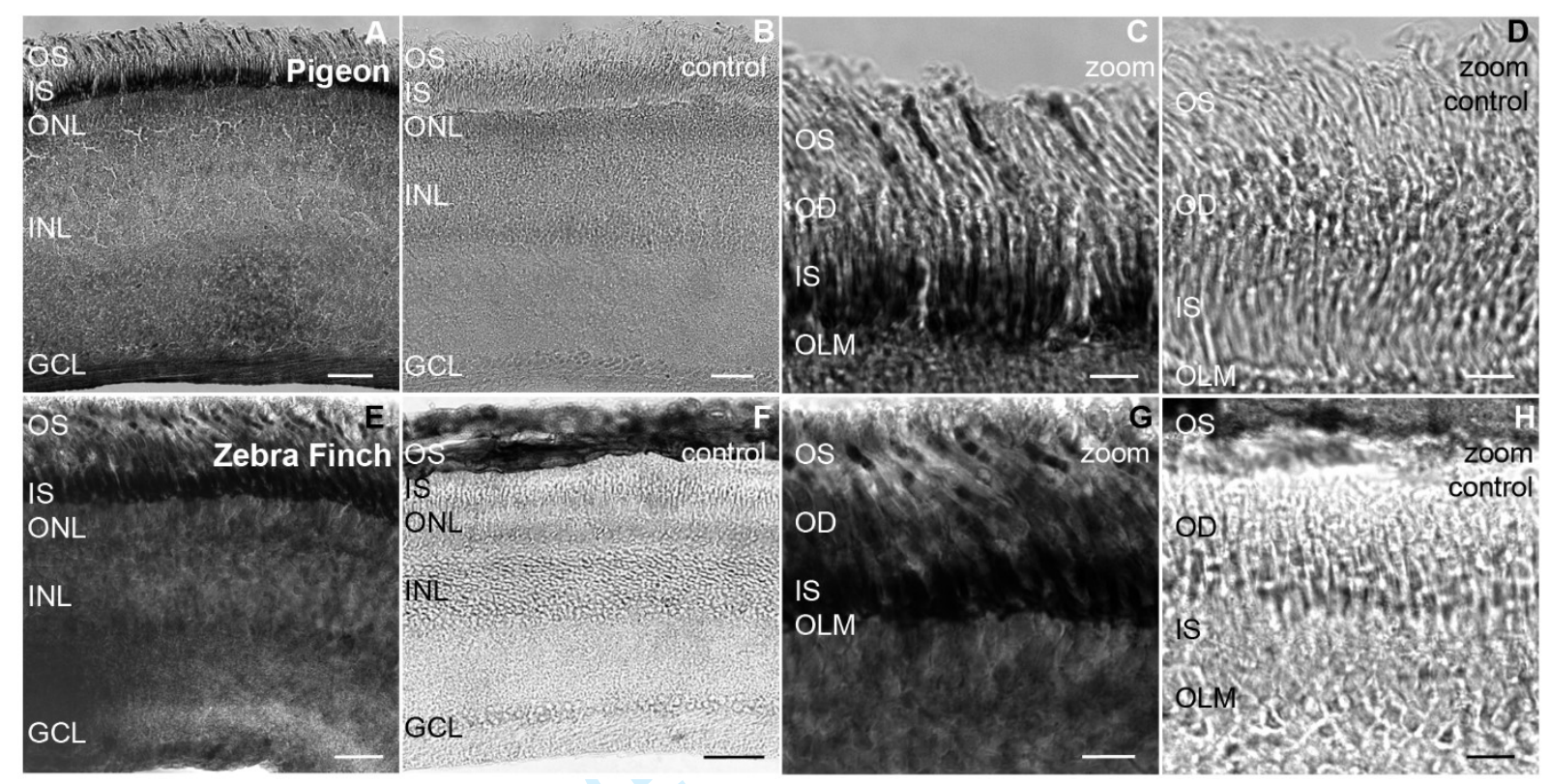

Fig. S1. Photoreceptor outer segment localisation of Cryla is confirmed in additional bird species with the gwCryla antibody. The antibody gwCryla labelled specific photoreceptor outer segments with the DAB staining method in retinae of the pigeon $(A, C)$ and the zebra finch $(E, G)$. When replacing the primary antibody with the pre-immune serum in retinal cryosections of the pigeon $(\mathrm{B}, \mathrm{D})$ and the zebra finch $(\mathrm{F}, \mathrm{H})$ we did not obtain any immunosignal by antibodies that had already been present in the animal before immunisation. All images for the respective species were taken from the same experiment with identical microscope settings. Scale bars: A-B, F $40 \mu \mathrm{m}$; C-D, G-H $10 \mu \mathrm{m}$; E $20 \mu \mathrm{m}$. OS, photoreceptor outer segments; OD, oil droplets; IS, photoreceptor inner segments; OLM, outer limiting membrane; ONL, outer nuclear layer; INL, inner nuclear layer; GCL, ganglion cell layer. 


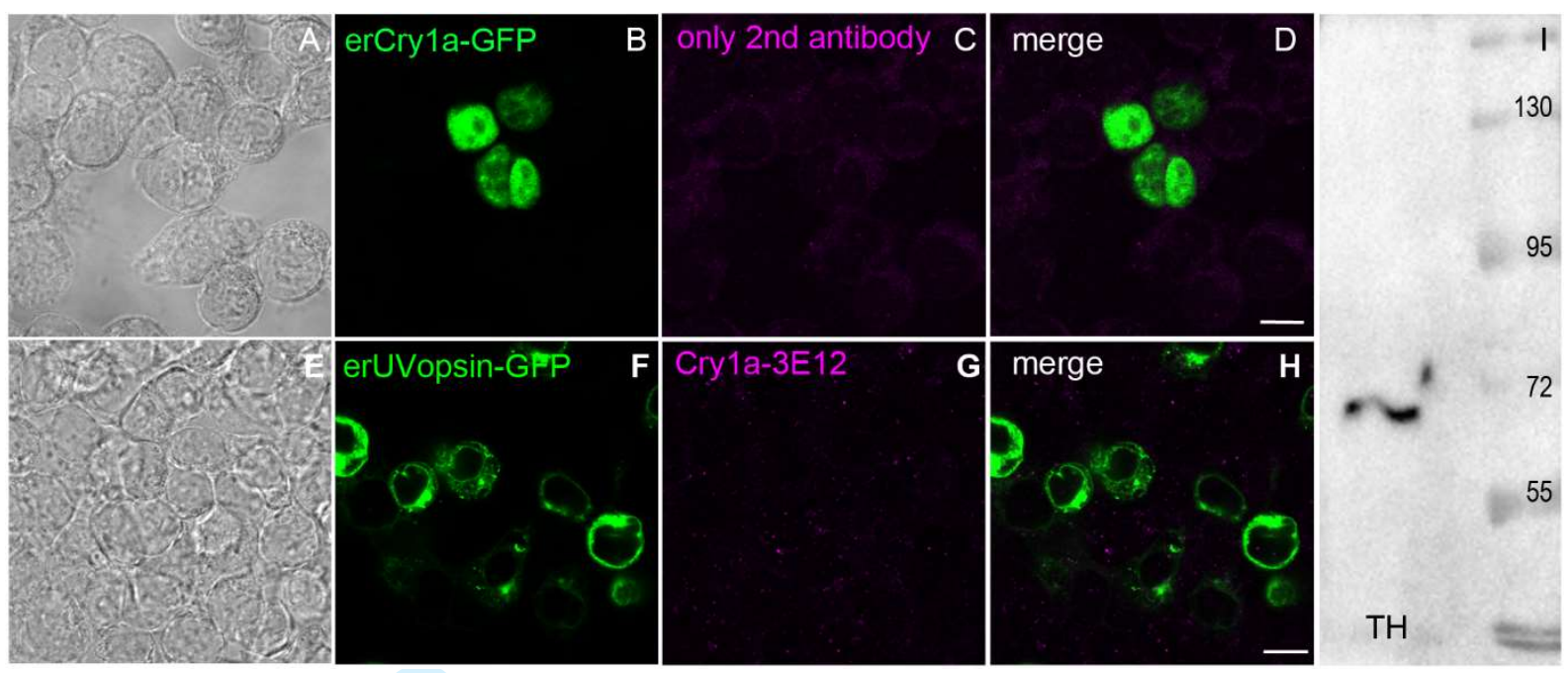

Fig. S2. Additional control for the Cry1a-3E12 antibody. When omitting the primary antibody on erCryla-GFP transfected cells (A-D), no antibody signal was detected. In immunocytochemical stainings on erUVopsin-GFP transfected HEK cells, the monoclonal Cryla-3E12 antibody did not recognise erUVopsin-GFP (E-H). In the immunoblot, the Cryla-3E12 antibody recognised a band of the expected size $(69.7 \mathrm{kDa})$ in total homogenate $(\mathrm{TH})$ of the chicken retina (I). Images A-H are single confocal scans; all images for the respective species were taken from the same experiment with identical microscope settings. Scale bars: $10 \mu \mathrm{m}$. 


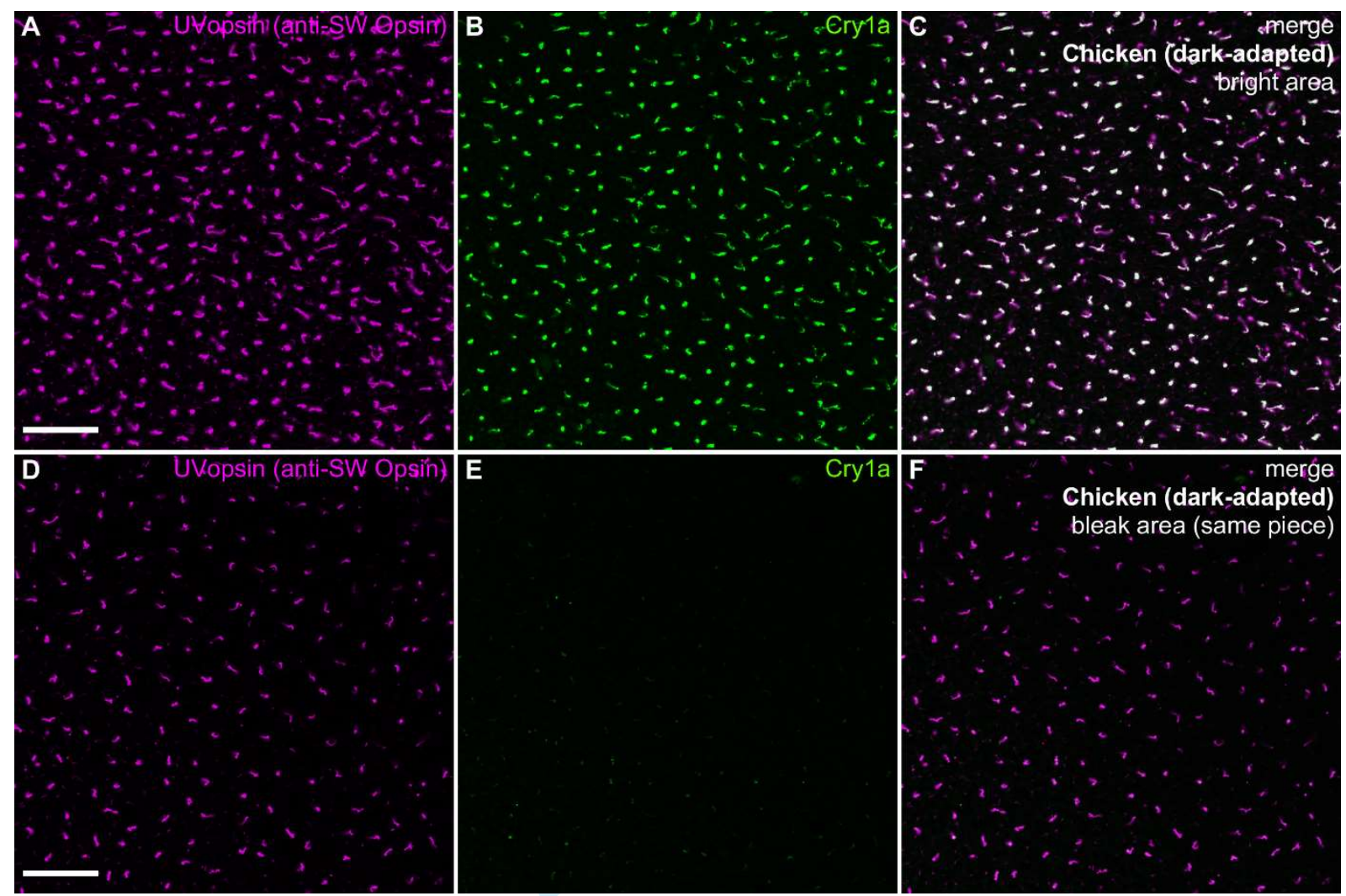

Fig. S3. Intensity of Cryla labelling can differ within the same specimen. In the staining of wholemounted retinae of the domestic chicken with the Cryla-3E12 antibody (green) and the UV/V opsin antibody (magenta), we found that the intensity of both Cryla and UV/V opsin can vary within the same retina piece. The intensity of the UV/V opsin labelling was not drastically different between the bright area (A) and the bleak area (D). However, the difference in the intensity of the Cryla labelling between the bright area (B) and the bleak area (E) was striking. All pictures were taken at the level of the outer segments. All images for the respective species were taken from the same experiment with identical microscope settings. Images were maximum projections of confocal stacks: seven sections, step size $0.42 \mu \mathrm{m}$. Scale bars: $50 \mu \mathrm{m}$. 